\title{
Reassessment and systematic position of the sinistral snails of genus Hemiplecta from Thailand (Eupulmonata: Ariophantidae), with description of two new species
}

\author{
Chirasak Sutcharit* \\ Animal Systematics Research Unit, Department of Biology, Faculty of Science, Chulalongkorn \\ University, Bangkok 1033o, Thailand \\ chirasak.s@chula.ac.th/jirasak4@yahoo.com \\ EkgachaiJeratthitikul* \\ Animal Systematics and Molecular Ecology Laboratory, Department of Biology, Faculty of \\ Science, Mahidol University, Bangkok 1040o, Thailand \\ ekgachai.jer@mahidol.edu
}

Piyoros Tongkerd

Animal Systematics Research Unit, Department of Biology, Faculty of Science, Chulalongkorn University, Bangkok 10330, Thailand

piyorose@hotmail.com

Somsak Panha

Animal Systematics Research Unit, Department of Biology, Faculty of Science, Chulalongkorn University, Bangkok 1033, Thailand

somsak.pan@chula.ac.th

\begin{abstract}
Indochina land snails of the family Ariophantidae are in need of thorough systematic revision. Here we comprehensively revise the systematics of the large-shelled, sinistral (counterclockwise) coiling snails from Thailand and Peninsular Malaysia. Molecular phylogeny based on mitochondrial (CoI and 16S) and nuclear $(28 \mathrm{~S})$ gene sequences demonstrates that these sinistral snails are not members of Dyakiidae as previously thought, but instead are more closely related to the genus Hemiplecta in the family Ariophantidae. Comparative morphology also reveals similarity of reproductive organ features (globular gametolytic organ, well-developed dart apparatus, and lack of amatorial organ complex). Based on this
\end{abstract}

\footnotetext{
* These authors should be considered joint first authors.

(C) CHIRASAK SUTCHARIT ET AL., 2020| DOI:10.1163/18759866-BJA10016

This is an open access article distributed under the terms of the CC-BY 4 .o license.
} 
evidence, we propose to transfer these sinistral snails to the genus Hemiplecta. Molecular phylogenetic analyses further strongly support the monophyly of this sinistral lineage with respect to other members of Hemiplecta. This monophyletic clade consists of five members including three species that were previously classified as "Dyakia", H. lahatensis, H. retrorsa and H. salangana, and two new species described herein, $H$. ligorica n. sp. and $H$. thailandica n. sp. This study also suggests that the anatomy of the gametolytic organ in the genus Hemiplecta corresponds well with the phylogenetic relationships and appears to be a taxonomically informative character, while the penial verge has little utility for generic recognition.

\section{Keywords}

Pulmonata - Dyakiidae - sinistral - endemic species - Indochina

\section{Introduction}

Southeast Asia has a diverse land snail fauna, and species vary greatly in size; shell diameter varies from half a millimeter (hypselostomatid; Schileyko, 1998; Páll-Gergely et al., 2015) to nearly seventy millimeters (i.e., ariophantids and dyakiids; Schileyko, 2002, 2003; Sutcharit et al., 2019). Traditionally, land snail classification has relied mainly on shell traits, and to a lesser extent has been based on reproductive anatomy. Several recent systematic studies have revealed considerable plasticity in morphological characteristics, and substantial incongruence between the morphology-based classification and molecular phylogenetic analyses. Such findings fuel the controversy over whether standard taxonomic methods are inadequate, and whether the distinct phylogenetic lineages derived from molecular data could facilitate the task of biological classification (Seberg et al., 2003; Tautz et al., 2003; Dunn, 2003; Hebert \& Gregory, 2005; Hirano et al., 2014; Köhler \& Criscione, 2015; Pholyotha et al., 2020).

In the present work, we revise the systematics of large-sized helicoid species assigned to the genera Hemiplecta Albers, 1850 and Koratia Godwin-Austen, 1919 (family Ariophantidae Godwin-Austen, 1883), as well as Dyakia Godwin-Austen, 1891 (family Dyakiidae Gude and Woodward, 1921) from Indochina. The genus Hemiplecta is widely distributed from India to Southeast Asia. This genus is characterized by a large shell and by globular shape of the gametolytic sac (Blanford \& Godwin-Austen, 19o8; Schileyko, 2002, 2015). The genus Koratia was treated as a subgenus of Hemiplecta by Zilch (1959) and Solem (1966), but was later elevated to genus rank by Schileyko (2002, 2015) based on the absence of a penial verge in the reproductive organ. The genus Dyakia, which was described to include several Greater Sunda Islands species, is characterized by both sinistral (counterclockwise) shell and the unique genitalia characters of the amatorial organ complex (Godwin-Austen, 1898; Schileyko 2003; Sutcharit et al., 2012, 2019). GodwinAusten (1898) was the first to revise the systematics of these snails and found that the sinistral species from the Malay Peninsula (Myanmar and Thailand) exhibit a distinct shape of the radula teeth. Laidlaw (1963) revised the taxonomy of Dyakia, but was uncertain about the Malay Peninsula species as they exhibited distinctive morphological character states (sculpturing as spiral wrinkles). Since then, the Southeast Asian helicoid snails with large and sinistral shells have consistently been attributed to the genus Dyakia s.l. (e.g., Panha, 1996; Maassen, 2001; Sutcharit et al., 2012). 
However, this largely shell-based classification has never been tested in a phylogenetic context. Given that shell characteristics have repeatedly been found to evolve convergently in a wide range of land snail taxa, such a phylogenetic analysis is crucial in creating a natural classification. The recent morphological revision of so-called "Dyakia" from Peninsular Malaysia clearly revealed that this grouping was polyphyletic, with Helix retrorsa Gould, 1843 and Nanina salangana Martens, 1883 found to display genitalia similar to Hemiplecta (Sutcharit et al., 2012). This contradiction indicates that most of the shell characteristics vary considerably within the higher taxonomic categories and thus are unreliable for classification. In addition, a large proportion of Indochinese land snail taxa are still known exclusively from their shells. The high similarity of shell morphology does not always indicate a common ancestry, but rather it may frequently reflect convergent evolution related to adaptations to varying environmental conditions (Vermeij, 1993; Hirano et al., 2015; Köhler \& Criscione, 2015), predation (Schilthuizen et al., 2006) or competition (Oheimb et al., 2018). Rather than shell features, the characters of the genital anatomy have been shown to be particularly informative for the recognition of taxa in many cases of the stylommatophoran groups, such as in the genera Macrochlamys Gray, 1847, Sarika Godwin-Austen, 1907 and Traphospira Blanford, 1905 (Pholyotha et al., 2018, 2020). Convergent shell features have also been found in many cases among the Australian camaenids (Köhler, 2010, 2011a, b, c, 2012; Köhler \& Shea, 2012).

Land snail surveys from southern Thailand and Peninsular Malaysia have yielded a number of the sinistrail snails that were preliminarily classified as the genus "Dyakia" based on their shell coiling. However, this classification has remained provisional. Better sampling and more data are needed to determine whether these sinistral species are members of Hemiplecta or Dyakia. Therefore, the primary objective of this study is to test the correspondence between traditional morphology by means of comparative study of key morphological characters (i.e., shell and genital anatomy) and the monophyletic groups based on molecular phylogeny of these sinistral snails. The proposed taxonomic rearrangement of Hemiplecta and Dyakia and descriptions of two new species are described herein, along with re-descriptions of the other three nominal species.

\section{Material and methods}

\section{Sampling and morphological examination}

Snails were sampled throughout eastern to southern Thailand and Peninsular Malaysia (fig. 1). The details of each locality are listed in table 1. Animal use protocol in this study was approved by the Chulalongkorn University Animal Care and Use Committee (CU-ACUC) under the approval number 1723018. Living snails were euthanized by a two-step method following AVMA Guidelines for the Euthanasia of Animals (AVMA, 2013). Foot tissues were cut and stored in 95\% ethanol before use for DNA extraction. Other remaining parts were preserved in $70 \%(\mathrm{v} / \mathrm{v})$ ethanol for anatomical purposes. The genital organs of $3-5$ specimens of each species were examined. Radulae were extracted, and examined under Scanning Electron Microscope (JEOL, JSM-541O LV). The radula shape and teeth formula were analyzed.

\section{Collection abbreviations}

CUMZ: Chulalongkorn University Museum of Zoology, Bangkok

NHMUK: The Natural History Museum, London 


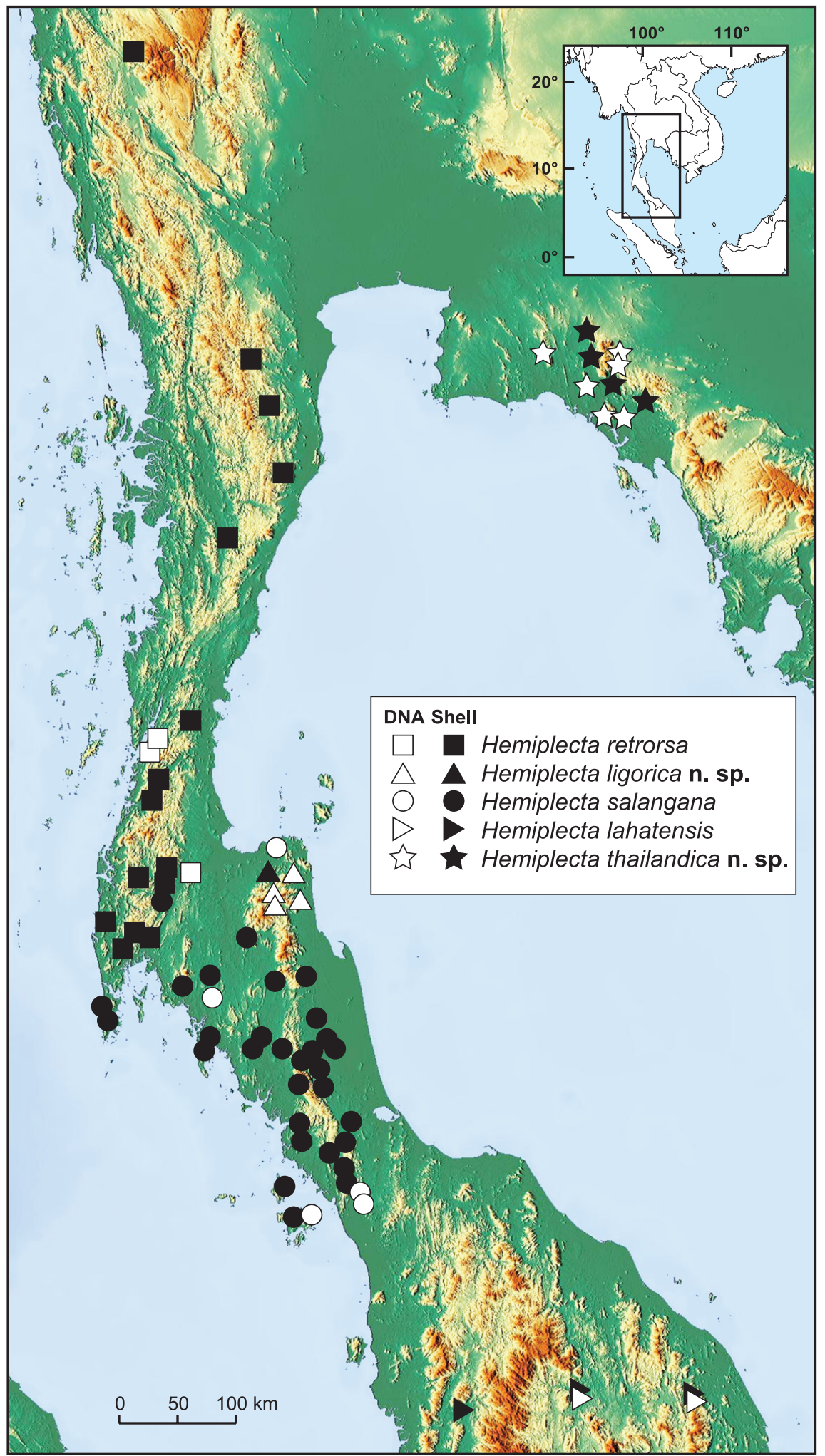




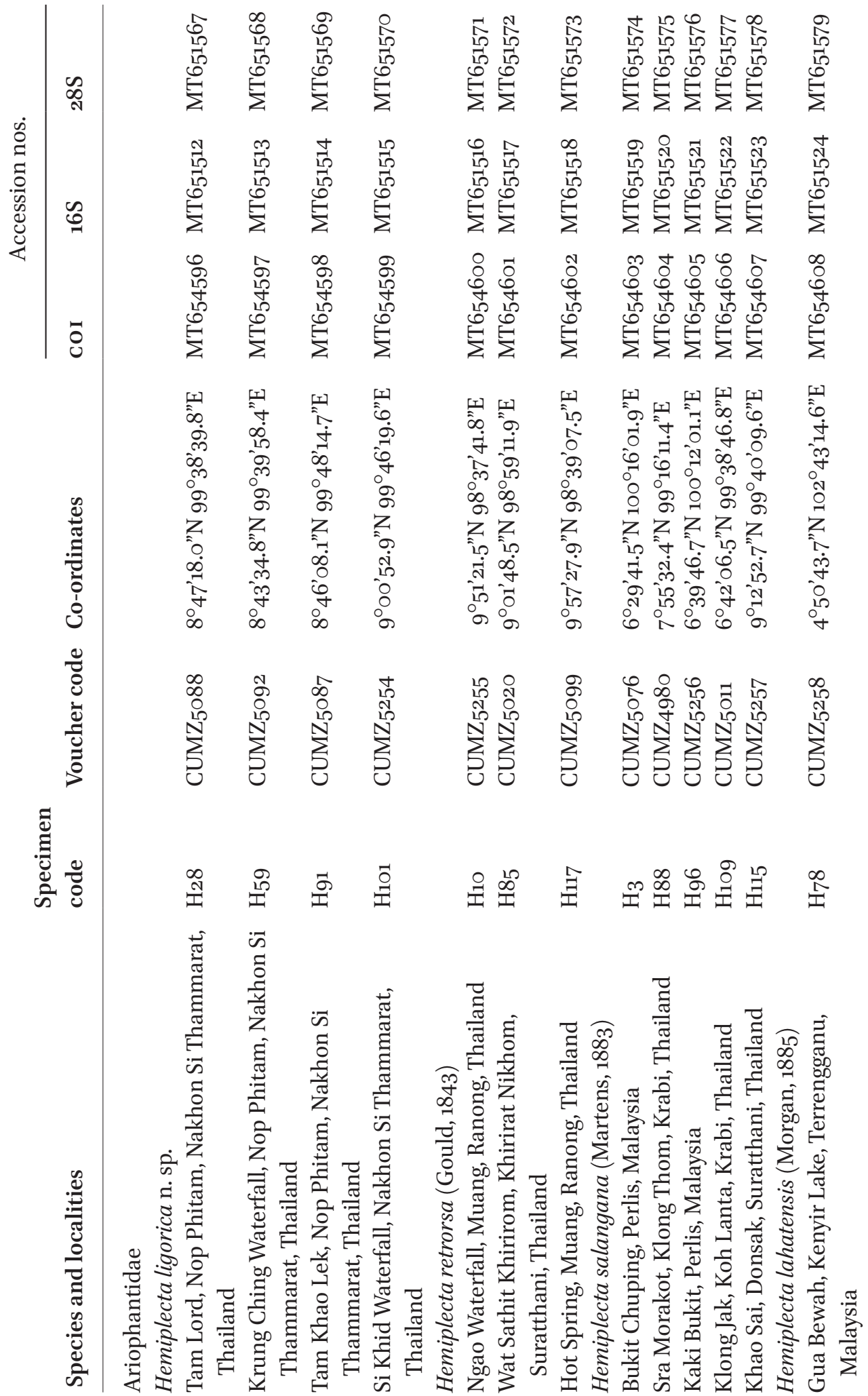




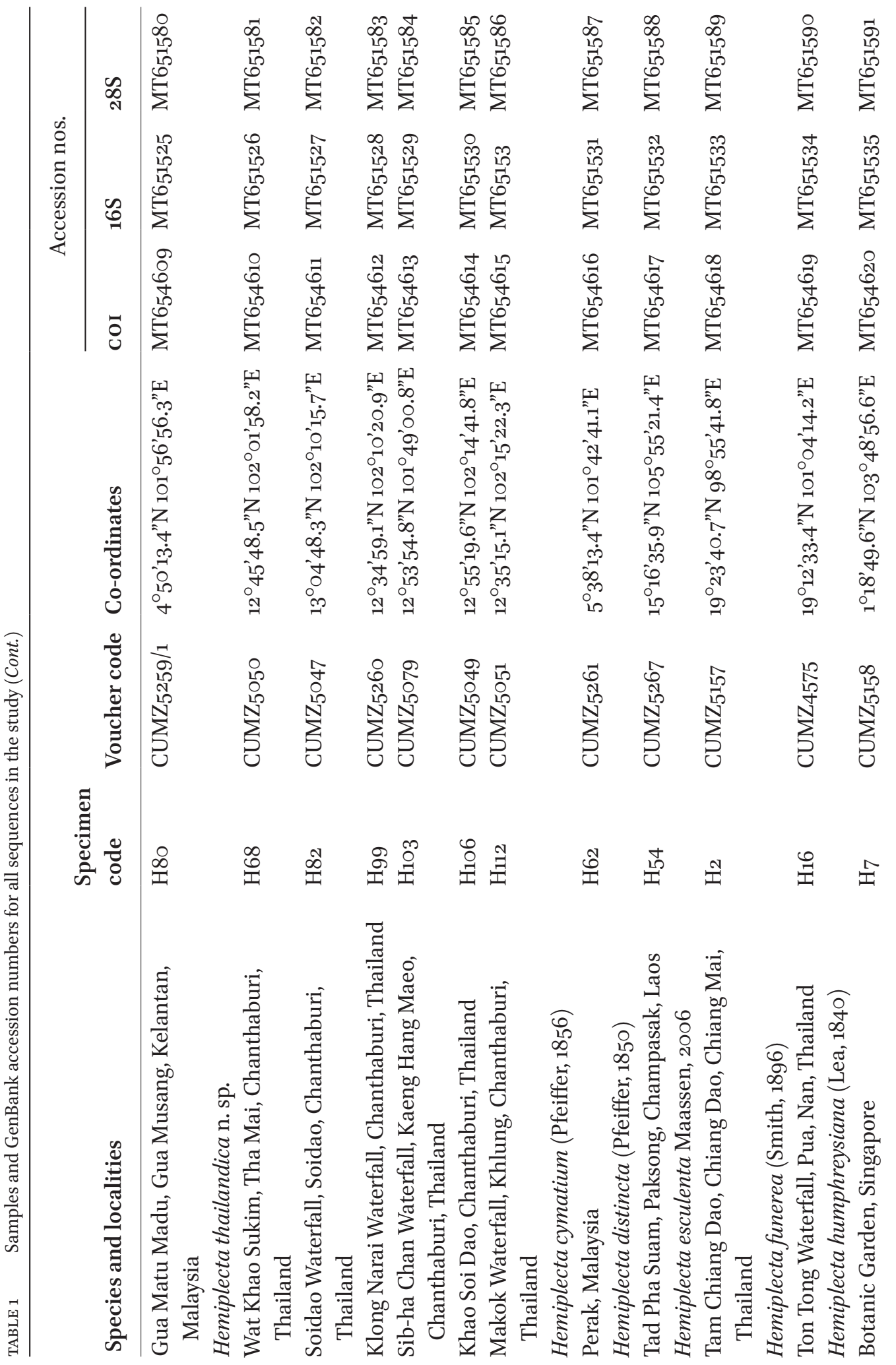




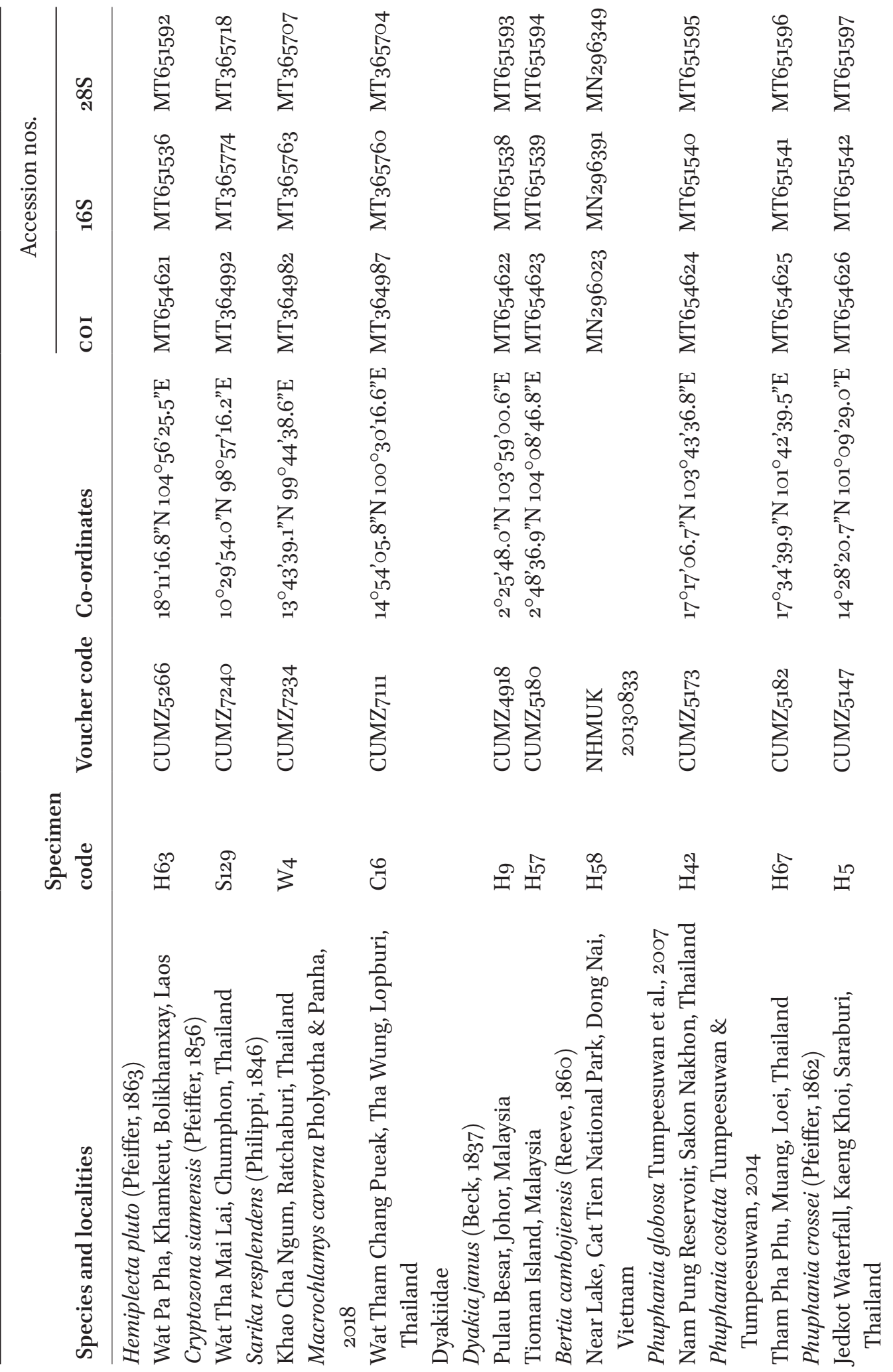




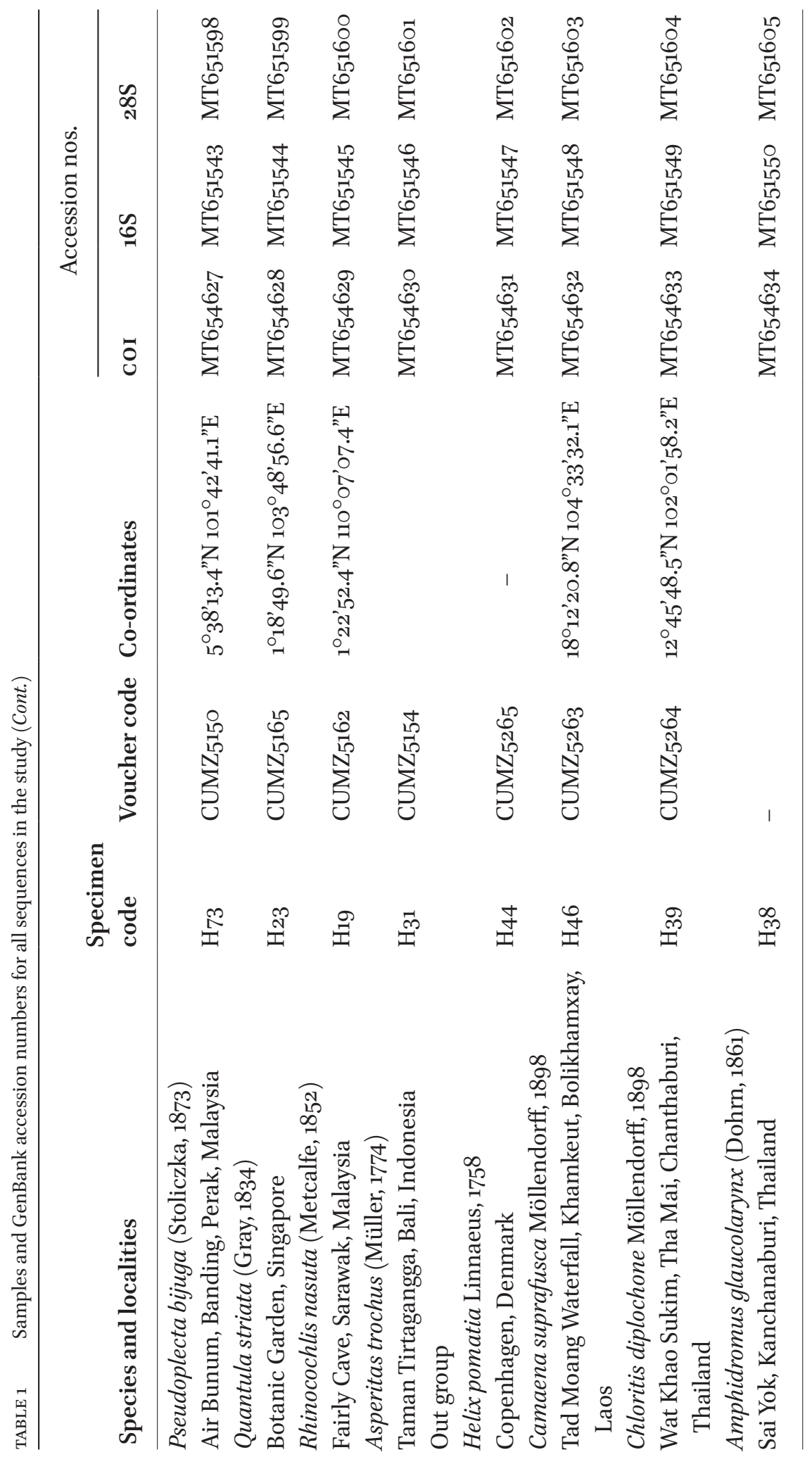


SMF: Forschungsinstitut und Naturmuseum Senckenberg, Frankfurt am Main

Zмв: Museum für Naturkunde, Humboldt University, Berlin

\section{Molecular studies}

Up to three specimens from each population and each recognizable morph were selected for DNA sequencing, with priority given to dissected individuals. Genomic DNA was extracted from the foot or mantle tissue using a NucleoSpin Tissue kit (MACHEREY-NAGEL), following the manufacturer's protocol. The mitochondrial cytochrome c oxidase subunit I gene (COI) was amplified using the universal primers LCO1490 G G T CAACAAAT CATAAAGATAT T G G and HCO2198 - TAAACTTCAGGGTGACCAAAAAATCA (Folmer et al., 1994), while the $16 \mathrm{~S}$ ribosomal RNA gene (16S) was amplified by primers $16 \mathrm{SsinF}$ GCCGCAGTACCTTGACTGTGCT or 16Sar CGCCTGTTTATCAAAAACAT with 16sbr CCGGTCTGAACTCAGATCACGT (Kessing et al., 1989), and the nuclear $28 \mathrm{~S}$ ribosomal RNA gene $(28 S)$ was amplified by primers $28 \mathrm{SF}_{4}-$ AGTACCGTGAGGGAAAGTTG and 28SR5 ACGGGACGGGCCGGTGGTGC (Morgan et al., 2002). The PCR amplification was conducted in a final volume of $20 \mu$ l containing $1 \mu \mathrm{l}$ of each primer (10 mM), $2 \mu \mathrm{l}$ of the extracted genomic DNA (25 ng), $7 \mu \mathrm{l}$ of distilled water, and $10 \mu \mathrm{l}$ of EmeraldAmp PCR Master Mix (TAKARA BIO INC.). Thermal cycling was performed at $94^{\circ} \mathrm{C}$ for $3 \mathrm{~min}$, followed by 35 cycles of $94^{\circ} \mathrm{C}$ for 3 o s, $51^{-60^{\circ} \mathrm{C}}$ (depending on samples and gene) for $60 \mathrm{~s}$, extension at $72^{\circ} \mathrm{C}$ for $1 \mathrm{~min}$, and then the final extension at $72^{\circ} \mathrm{C}$ for $5 \mathrm{~min}$. All PCR products were purified by PEG precipitation and then commercially sequenced by an automated sequencer (ABI prism 373OXL) with the same primers in both directions. Newly obtained nucleotide sequences were deposited in the
GenBank database (see table 1 for accession numbers).

\section{Phylogenetic analysis}

Sequences were edited and aligned using ClustalW, implemented in MEGA7 (Kumar et al., 2016). The final concatenated alignment used in phylogenetic tree construction contained 1576 bp: 655 bp of $C O I, 369$ bp of $16 S$, and $55^{2}$ bp of $28 S$. These sequences came from 43 specimens representing seven genera of Dyakiidae and four recognized genera of Ariophantidae occurring in Thailand, along with specimens of the non-limacoid taxa Camaenidae and Helicidae as outgroups. The details of taxon sampling used in phylogenetic analysis are shown in table 1 . Most of the sequences in this study were newly obtained from 42 specimens, but some sequences were retrieved from previous studies (i.e., Sutcharit et al., 2019 and Pholyotha et al., 2020).

The best-fit model of nucleotide substitution and the best partitioning scheme were identified by PartitionFinder2 v.2.3.4 (Lanfear et al., 2016), by using a heuristic search algorithm under the Akaike Information Criterion (AIC). The partitioned concatenated dataset was then used to infer the phylogenetic relationship by using Bayesian inference (BI) and maximum likelihood (ML) analyses, implemented in CIPREs Science Gateway (Miller et al., 2010). The ML analysis was performed using RAxML v.8.2.10 (Stamatakis, 2014). The GTRGAMMA was set as the model for all gene partitions. One thousand ML bootstrap replicates were performed to assess topology support. The BI trees were estimated by running a 10 million generation Metropolis-coupled Markov chain Monte Carlo (MC-MCMC) as implemented in MrBayes 3.2.6 (Ronquist et al., 2012). The best-fit models for each partition followed the PartitionFinder2 results. Each MCMC consisted of two runs with four chains, one chain of which was heated. A data 
partition was applied that allowed parameters to be estimated separately for each partition. Sampling rate of the trees was once every 1000 generations. Stationarity was considered to have been reached when the average standard deviation of split frequencies shown in MrBayes was less than 0.01 and the log likelihood of sampled trees reached a stationary distribution. The first $25 \%$ of obtained trees were discarded as burn-in. The remaining trees were used to estimate the consensus tree topology, bipartition posterior probability (bpp) and branch lengths. Nodes with bipartition posterior probabilities (bpp) greater than 0.95 of BI analysis supported and/or bootstrap support values larger than 70 of ML analysis were considered as supported nodes (Huelsenbeck \& Hillis, 1993; Larget \& Simon, 1999). Genetic divergence based on COI sequences among pairwise OTUs was also calculated using uncorrected p-distances as implemented in MEGA7 (Kumar et al., 2016).

\section{Results}

Molecular phylogenetic trees were reconstructed based on the concatenated mitochondrial $C O I$ and $16 S$ genes, and as well as nuclear $28 S$ sequences obtained from 43 individuals. This concatenated dataset was divided into five partitions, consisting of partitions for $16 S$ and $28 S$ genes, and for each of three codon positions of the $C O I$ gene. The best-fit models for each partition were $G T R+G$ for the first codon position of $\mathrm{COI}$ and $16 \mathrm{~S}$, $\mathrm{GTR}+\mathrm{I}+\mathrm{G}$ for the second codon position of COI and 28S, and GTR+I for the third codon position of $\mathrm{COI}$ genes. Both maximum likelihood (ML) and Bayesian inference (BI) analyses produced trees with identical topologies, and with all major clades relatively well supported. Therefore, only the tree topology from BI is presented in fig. 2. Overall, our phylogeny is largely congruent with the current generic and familial classification with the notable exception that some sinistral species currently treated as members of the genus Dyakia (Dyakiidae) cluster closely together with species of the genus Hemiplecta (Ariophantidae). However, these two families are distinctly recognized by the comparative morphology of shells and genitalia.

All nominal genera that were placed in the Dyakiidae based on their morphology are recovered as one major clade in our tree. However, Dyakia, as presently delineated, is non-monophyletic. While D. janus (Beck, 1837) is nested with the dyakiid clade, five other species assigned to this genus are placed among the Ariophantidae, and more specifically, within the genus Hemiplecta. The relationships among other dyakiid genera, mostly represented by the type species, are well supported in both BI and ML analyses. Three sinistral genera, Dyakia, Rhinocochlis Thiele, 1931 and Bertia Ancey, 1887 are not recovered as monophyletic. All three species of the Phuphania Tumpeesuwan et al., 2007 form the sister group to Quantula striata (Gray, 1834). The clade containing the ariophantid genera, Cryptozona Mörch, 1872, Macrochlamys and Sarika forms a sister group to Dyakiidae, with strong support from both ML and BI analyses.

The other major clade consists of the remaining ariophantids, including the genera Hemiplecta and Koratia, and the five sinistral snails that were provisionally classified as "Dyakia" species from southern Thailand and Peninsular Malaysia. Three of these have previously been identified as nominal species, "Dyakia" retrorsa, "Dyakia" salangana, and "Dyakia" lahatensis (Morgan, 1885a), whereas the other two represent putative newly discovered species. The phylogenetic tree also reveals that all these five sinistral species form a monophyletic clade and that 


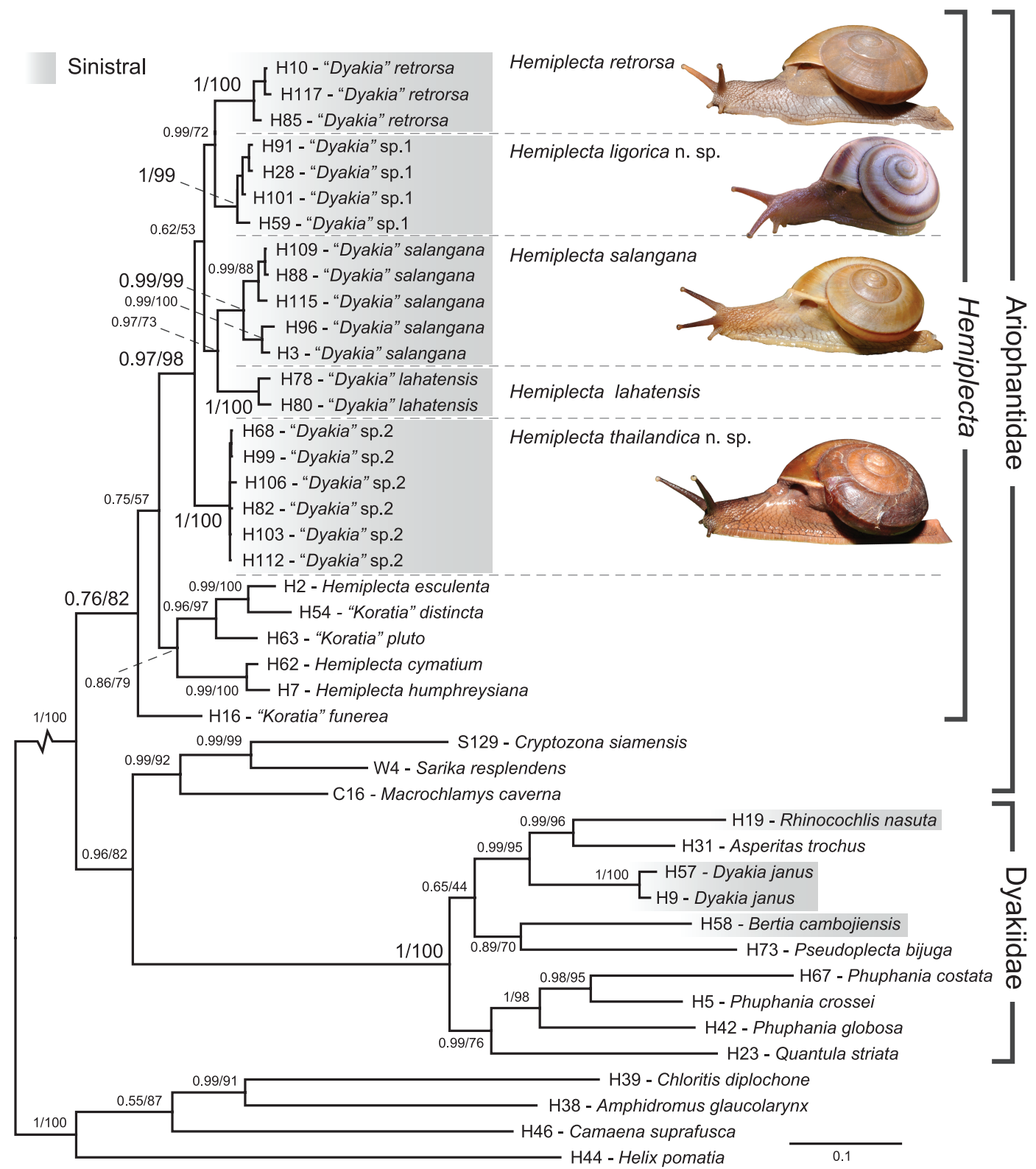

FIGURE 2 Bayesian inference tree based on $1576 \mathrm{bp}$ concatenated alignment dataset of $\mathrm{COI}+16 \mathrm{~S}+28 \mathrm{~S}$ genes. Numbers on nodes indicate bootstrap values from maximum likelihood $(\mathrm{ML})$ and bpp from Bayesian inference analysis (BI), and are shown as BI/ML. Images of living specimens are not to scale.

this clade is sister to the other members of the genus Hemiplecta and Koratia. Within this clade, "Dyakia" retrorsa is most closely related to "Dyakia" sp. 1 from Nakhon Si Thammarat, Thailand. "Dyakia" salangana is sister to "Dyakia" lahatensis, while "Dyakia" sp. 2 from eastern Thailand is the sister lineage of the above four species.

The genus Koratia (type species: Helix distincta Pfeiffer, 1850) does not form a monoplyletic clade based on the present analysis. "Koratia" distincta and "Koratia" pluto (Pfeiffer, 
1863) is clustered with $H$. esculenta, H. cymatium, and $H$. humphreysiana (the type species of Hemiplecta), while "Koratia" funerea (Smith, 1896) is placed as a basal taxon to other Hemiplecta species.

Within the genus Hemiplecta, the average genetic distance was estimated to be $8.14 \%$ (table 2). The minimum divergence is $2.92 \%$ between the pair of $H$. cymatium (Pfeiffer, ${ }_{1856)}$ ) and $H$. humphreysiana, while the maximum divergence is $9.75 \%$ between "Dyakia" salangana and $H$. humphreysiana. Among the five sinistral "Dyakia" snails, the average genetic distance ranges from $5.83 \%$ to $7.46 \%$. The intraspecific genetic distances for these species are relatively low, except in "Dyakia" salangana, where the structured subclades show a considerable divergence of 3.03\% between Thai and Malaysian populations.

All systematic descriptions and related remarks are presented as Appendix.

\section{Discussion}

\section{Evolution of the sinistral clade within the dextral-dominated genus}

Current systematic classification of the Dyakiidae and Ariophantidae is still heavily influenced by traditional shell-based characters, and is sometimes incongruent with molecular phylogeny (Hyman et al., 2007, 2017; Köhler et al., 2020). Diagnostic characters of reproductive organs in Dyakiidae are the presence of amatorial organ complex (amatorial organ gland and duct) and the connection of the gametolytic organ to the amatorial organ (Laidlaw, 1931; Hausdorf, 1995; Sutcharit et al., 2012). However, unique characters of the Ariophantidae are still equivocal. Most of the known taxa are described based solely on their shells, and without genitalia characters. Moreover, a conclusive phylogeny is still far from complete. Nevertheless, the currently accepted defining character states of the Ariophantidae include the presence of shell lobes, caudal foss, and well-developed caudal horn, either absence or presence of amatorial organ (but if present, without accessory organs), and a gametolytic organ that is attached to the vagina (Hausdorf, 1998; Schileyko, 2002; Hyman \& Ponder, 2010). The present phylogeny reveals that five sinistral species are clustered with the dextrally-coiled genus Hemiplecta (Ariophantidae), although sinistrality has long been considered as a diagnostic character of Dyakia s.s. (GodwinAusten, 1891; Laidlaw, 1931; Schileyko, 2003). This phylogenetic grouping is supported by the anatomy of reproductive organs. The genitalia of sinistral clade resembled those of Hemiplecta instead of the Dyakia. Only the reversed genital opening on the body side was detected between opposite coiling snails (Sutcharit et al., 2012; this study). Normally, the reproductive anatomy in stylommatophorans is highly asymmetric, and the sinistral individuals have identical genital structure as a mirror-image to other dextral individuals of the same taxa (Gittenberger, 1988).

From our multi-locus phylogeny, sinistrality thus is not a trait unique to Dyakia but has convergently evolved in Hemiplecta as well. Sinistrality has sporadically evolved and has occurred independently among different stylommatophoran clades (Asami et al., 1998; Sutcharit et al., 2007; Hoso et al., 2010; Jirapatrasilp et al., 202O). In our results, the sinistral shell coiling has become fixed within this Hemiplecta clade, similar to the Japanese endemic genus Euhadra Pilsbry, 1890, of which four out of about 20 species are sinistral and all are derived from a single sinistral ancestor (Ueshima and Asami, 2003; Davison et al., 2005). In other cases, dextral and sinistral individuals co-occur in the same population (chirally dimorphic). For example, in 





the Southeast Asian endemic tree snail genus Amphidromus Albers, 1850, which comprises two subgenera. One subgenus, Amphidromus, includes chirally dimorphic species, while another subgenus, Syndromus Pilsbry, 1900, includes only sinistral species. Phylogenetic analysis has shown that sinistrality has persisted as the ancestral state of the sinistral Syndromus clade (Sutcharit et al., 2007), which is similar to the case of the sinistral Hemiplecta clade in this study.

It is interesting to consider how sinistrality has evolved independently within the genus Hemiplecta, where dextrality is the dominant or more common morphology. One of the likely explanations is predation pressure. A comparative survey of the diversity of the sinistral snails as potential prey (i.e,. those with lower-spired shells) showed that the sinistral taxa occur more commonly within the distribution range of a snail-eating snake (genus Pareas) (Hoso et al., 2010). In feeding experiments, snail-eating snakes tended to prey on dextral over sinistral individuals. This survival advantage of sinistral individuals is more likely to enhance the chance of population fixation by complete premating isolation (Hoso et al., 2007, 2010; Danaisawadi et al., 2016). Another predation experiment revealed that snail-eating snakes avoided approaching or striking at a sinistral snail ("Dyakia" salangana), suggesting it was more difficult and costlier to handle than dextral snails (Danaisawadi et al., 2016). The adult Hemiplecta spp. have much greater shell size than the predation threshold size; however, these large snails can be small enough to be preyed upon when they are young. The factor of snake predation may counterbalance the disadvantage in copulation, and if the sinistral phenotype exceeds $50 \%$ under selective advantage, this phenotype would become fixed for the population (Gittenberger, 1988; Johnson et al., 1990; Asami et al., 1998; Ueshima and Asami, 2003;
Davison et al., 2005; Gittenberger et al., 2012). Moreover, many studies have shown that interchiral mating (copulation between individuals with opposite coiling direction) is almost impossible in low-spired snails (shell width greater than shell height) that generally perform simultaneous reciprocal copulation. Thus, reverse coiling populations would become isolated rapidly and give rise to a single-origin sinistral clade through a complete premating isolation mechanism (Batenburg \& Gittenberger, 1996; Gittenberger, 1988; Asami et al., 1998; Reise et al., 2002; Gittenberger et al., 2012).

\section{Taxonomic implications in Hemiplecta}

The genus Hemiplecta currently comprises at least twenty nominal species, with most known by shell characteristics only (Schileyko, 2002). The anatomy of the type species, H. humphreysiana, was described by Collinge (1902) and Blanford \& Godwin-Austen (1908), and that of $H$. cymatium and $H$. distincta was described by Stoliczka (1873), Godwin-Austen (190o, 1919), and Schileyko (2002). The conic to depressed-conic shell, globular gametolytic sac with undifferentiated gametolytic duct, very short flagellum, and short to long epiphallic caecum have been recognized as characters unique to the genus (Schileyko, 2002, 2015). The function of the epiphallus and epiphallic flagellum is thought to produce the spermatophore, the tail-pipe forming in the flagellum, and the capsule in the epiphallus. The epiphallic caecum is believed to function in turning the spermatophore so that the tail-pipe is moved into the penis first (Gómez, 2001).

The nominal genus Koratia was previously treated as a distinct genus based on the absence of a penial verge inside the penis (table 3; Godwin-Austen, 1919; Schileyko, 2002). However, our phylogenetic analysis indicates that three nominal species 


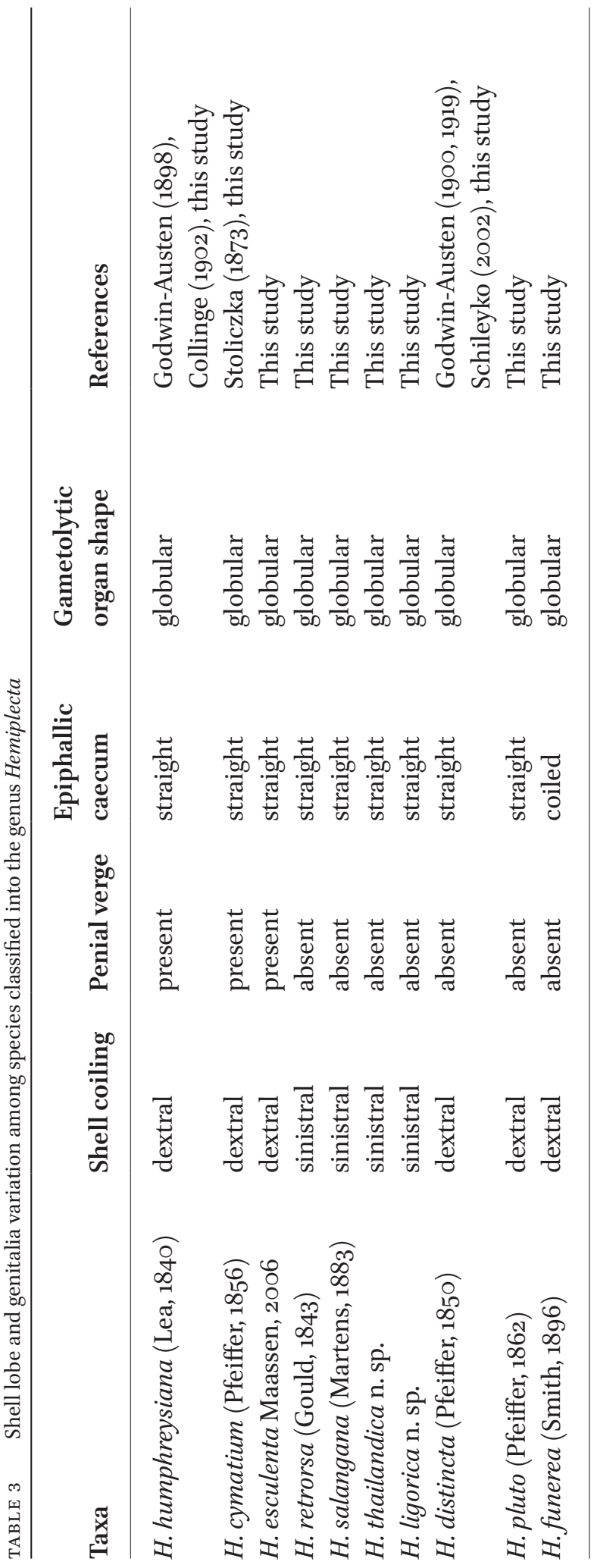


previously assigned to the Koratia do not form a monophyletic group but instead are nested with other Hemiplecta (fig. 2). Therefore, absence of a penial verge may be attributed to the reproductive plasticity in Hemiplecta s.l. Our analysis also emphasizes the importance of describing genitalia along with other characters when defining these diverse taxonomic groups. In view of our molecular results, Koratia should no longer be considered as a separate genus.

Within the sinistral clade, this study elucidates the presence of five genetically distinct and morphologically divergent lineages, which we recognize here as distinct species, namely $H$. retrorsa, $H$. salangana, $H$. lahatensis, and two newly proposed species: $H$. ligorica $\mathrm{n}$. sp. and $H$. thailandica $\mathrm{n}$. sp. The divergence values among them are high (5.83-7.46\%) when compared with the approximately $4 \%$ of the optimum intra/interspecific threshold value in stylommatophoran land snails (Davison et al., 2009). The deep divergence detected here is similar in order of magnitude to that in other land snails reported elsewhere; for example, about 6-12 \% among Australian camaenid species (Criscione et al., 2012). Furthermore, the molecular phylogenetic results also confirm the validity of $H$. funerea as a genetically distinct species and undoubtedly support the specific validity of $H$. pluto. Traditionally, these two species have been recognized as a subspecific entity or a synonym, respectively, of $H$. distincta (Fischer \& Dautzenberg, 1904; Schileyko, 2011). Only the recent treatment by Inkhavilay et al. (2019) has raised them to a specific level, but without clear supporting evidence.

Currently, the sinistral clade comprises five nominal species, four of which were anatomically examined, with the exception of $H$. lahatensis. This species possesses a sinistral shell with a wrinkled shell surface, and its distribution covers the northern part of Peninsular Malaysia; it likely belongs to the Hemiplecta.
Further examination of newly-collected adult specimens are necessary to confirm this species' generic position and morphological relationship with other sinistral-shelled taxa.

In terms of distribution, four of the species range from the southern Tenasserim Range through the Malay Peninsula. The exception is $H$. thailandica n. sp., which is restricted to Indochina (Eastern Thailand) and probably in Cambodia (Sutcharit et al., 2O2O); this could be attributed to allopatric speciation. This close relationship between the Malay Peninsula and Indochina populations has been similarly reported in various land snail groups and also in other animals, including butterflies and centipedes (Muadsub \& Pinkaew, 2014; Siriwut et al., 2015). These repeated disjunct distribution patterns are indicative of a cause that is linked to the geographical history of Sundaland. The fluctuation of sea level in the South China Sea contributed to the exposure of rainforest connection between Indochina and the Malay Peninsula (Voris, 200o; Woodruff, 2010; Lukoschek et al., 2011).

The most consistent and reliable character for species delimitation in every species of land snail is the internal anatomy of the penis, along with other genital characters relating to the penis and epiphallus, whereas the gametolytic organ was informative at the genus level (Hyman et al., 2017; Jirapatrasilp et al., 202O; Pholyotha et al., 202O; Siriboon et al., 2020). For example, reproductive organs are highly consistent in the dark shell and yellow shell forms (C. Sutcharit, unpublished data) of $H$. funerea, (i.e., coiled epiphallic caecum and penial verge absent; table 3 ). This supports the hypothesis that reproductive anatomy is an important factor in species recognition during copulation. In contrast, when delineating species by their shell morphology, the shape and coiling are of little value. The shell banding patterns are readily recognizable in some living species, e.g., H. ligorica n. sp., by its small 
and banded shell. However, this feature may be more difficult to distinguish in bleached, dead shells. Another pair of species that co-occur, $H$. pluto and $H$. distincta, can reliably be distinguished in life by their red or brownish body color, respectively (see Inkhavilay et al., 2019: fig. 56c, d), although the colors are faded in alcohol-preserved specimens.

\section{Conclusion}

Based on phylogenetic results and morphological information in the present study, we have transferred the sinistral species previously and incorrectly assigned to Dyakia (family Dyakiidae) to the genus Hemiplecta (family Ariophantidae). Two previously unrecognised species are described based on consistent differentiation in molecular, shell, and genitalia characters. Our data also provide further support for three other sinistral Hemiplecta species, which are also re-described herein. The results also suggest the synonymization of the formerly recognized as (sub)genus Koratia under the Hemiplecta. Finally, the results indicate the evolutionary instability of shell traits that are often used for land snail classification, while genital characters are highlighted as reliable taxonomic markers for delimiting species and at least some higher taxa. The integration of multiple independent characters including molecular evidence is crucial for delimiting higher systematic levels.

\section{Acknowledgements}

The authors are grateful to all members of the Animal Systematics Research Unit, Chulalongkorn University for their kind help during field trips. The authors are also indebted to J. Ablett, F. Naggs and H. Taylor
(NHM, London), R. Janssen, K.-O. Nagel and S. Hof (SMF, Frankfurt), T. von Rintelen and C. Zorn (ZMB, Berlin) for allowing the authors to examine the material housed in the type collections, the type material database, and photographs. This project was mainly funded through grants received from the Plant Genetic Conservation Project under the Royal Initiative of Her Royal Highness Princess Maha Chakri Sirindhorn, Chulalongkorn University, the TRF Strategic Basic Research DBG 6o80o11 (2017-2019) and the Thailand Research Fund (TRF-DPG628ooo1). We also wish to thank the anonymous reviewers for critically reviewing the manuscript.

\section{APPENDIX}

\section{Systematics}

Family Ariophantidae Godwin-Austen, 1888 Genus Hemiplecta Albers, $185^{\circ}$

Hemiplecta Albers, 1850: 6o, 61. Albers, 186o: 52, 53. Zilch, 1959: 317. Schileyko, 2002: 1282,1283 .

Koratia Godwin-Austen, 1919: 202. Zilch, 1959: Schileyko, 2002: 1281, 1282. New synonym

Ariophanta (Semperia) Godwin-Austen, 1898: 82 [non Crosse, 1867: 74, 75]. New synonym

Semperia: Blanford \& Godwin-Austen, 1908: 299. Zilch, 1959: 313 .

Dyakia (Semperia): Baker, 1941: 267. Schileyko, 2003: 1363 .

Type species. Helix humphreysiana Lea, 1840; subsequent designation by Martens in Albers, 186o: $5^{2}$.

\section{Description}

Shell. Shell medium to large, conic to depressed conic and dextral or sinistral. Shell color monochrome brownish or whitish 
and with or without spiral band. Last whorl rounded to keeled and little descending near aperture. Apertural lip simple to slightly thickened in adult snails. Umbilicus narrowly open.

Genitalia. Genitalia with long cylindrical tubular penis, thin penial sheath, and penial verge may be present or absent. Penial retractor muscle attached at tip of a straight or coiled epiphallic caecum; flagellum short. Dart apparatus well developed. Gametolytic organ (without distinct duct) with globular or bulbous sac.

Radula. Radula with symmetric unicuspid central tooth; asymmetric unicuspid lateral teeth. Marginal teeth curved and bicuspid. Jaw smooth (without vertical ribs), crescentic, with anteriorly convex cutting margin.

External features (fig. 2). Living snail with long and brownish to dark brown tentacles. Skin reticulated brown with dark brown reticulations over the entire body. Mantle with well-developed dorsal lobes; short and finger-shaped shell lobes may be absent or present. Foot unipartite and pedal groove typical of aulacopods. Caudal horn not overhanging; caudal foss, short vertical slit in tail above sole margin and well defined.

Distribution. The range of this genus is from Southeast Asia to New Guinea. The records from India and Maldives are ambiguous and need further study (Blanford \& GodwinAusten, 1908; Schileyko, 2002).

Remarks. Historically, Godwin-Austen (1898) revised the systematics of the ariophantid snails in British India and Burma (today in South Asia and part of Southeast Asia). He found that the sinistral species, especially from Burma [Myanmar] tended to have radula teeth distinctly different from the typical Ariophanta from India. This character agrees with some Sumatra and Sulawesi species as reported by Semper (1870). Later, Laidlaw (1931) revised the genus of sinistral species and reported similar results, suggesting that the taxonomic position of sinistral species from Myanmar and Thailand needed revision. Then, Godwin-Austen (1898: 82) proposed the name "Semperia" as a subgeneric division of Ariophanta with Helix retrorsa Gould, 1843 as the type species. Unfortunately, this genus-group name was preoccupied by Crosse (1867) for fissurarellid limpets. In addition, this nominal subgenus has not been widely accepted as valid.

\section{Hemiplecta retrorsa (Gould, 1843)}

(figs 1, 3A, B, 5A, B, 6A-C)

Helix retrorsa Gould, 1843: 139. Type locality: Tavoy, British Burma. Pfeiffer, 1848: 76. Pfeiffer, 1876: 128. Hanley and Theobald, 1876: pl. 25, fig. 6.

Helix (Caracolla) retrorsa: Gould, 1844: 455, pl. 24, fig. 5 .

Ariophanta retrorsa: Godwin-Austen, 1883: 133, 136, 137, pl. 34, figs 4, 5, 7, 8 .

Ariophanta (Semperia) retrorsa: GodwinAusten, 1898: 82.

Dyakia retrorsa: Blanford \& Godwin-Austen, 1908: 300. Laidlaw, 1931: 191. Laidlaw, 1963: 145 .

Material examined. Type material: syntype MCZ 16933 (1 shell; fig. 3A) from Tavoy British Burma [Dawei District, Tanintharyi Region, Myanmar]. Non-type material: THAILAND: Ta Kien Thong Waterfall, Sangkhlaburi District, Kanchanaburi Province: CU Mz 5og6. Kaeng Kracharn National Park, Phetchaburi Province: CUMZ 5021, 5025. Kui Buri National Park, Prachuapkhirikhan Province: CUMz 5039. Pala-U Waterfall, Hua Hin District, 


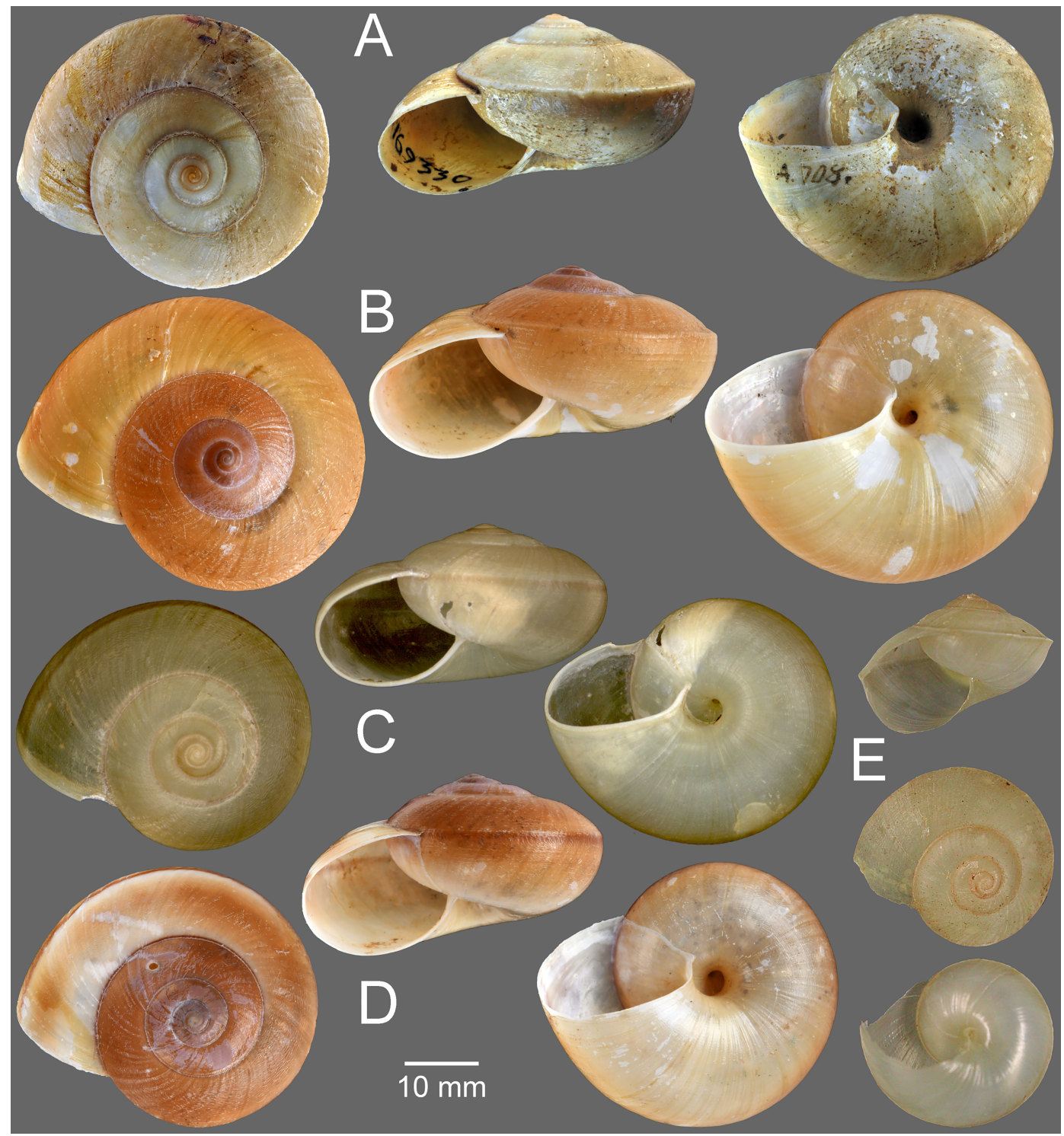

FIGURE 3 Shell characters. A, B. Hemiplecta retrorsa, (A) syntype MCZ 169330 and (B) specimen CU MZ 5099 from Ranong Province. C, D. Hemiplecta salangana, (C) syntype ZMB/Moll 32578 and (D) specimen CUMZ 4967 from Phuket Province. E. Hemiplecta lahatensis, syntype MNHN-IM-20oo-22834.

Prachuapkhirikhan Province: CUMz 5036, 5044, 5046. Tam Phu Ta-kien, Tha Sae District, Chumporn Province: CUMz 5032. Boonya Bann Waterfall, Muang District, Ranong Province: CUMZ 5045. Hot Spring, Muang District, Ranong Province: CUMZ 5024, 5094, 5099 (fig. 3B). Khao Narai, Kapoe District, Ranong Province: CUMz 5081. Tone Phet
Waterfall, Muang District, Ranong Province: CUMz 5028. Khao Lak National Park, Thai Mueang District, Phang Nga Province: CUMz 5019, 5038. Tam Nam Put, Thap Put District, Phang Nga Province: CUMz 5035, 5091. Tao Thong Waterfall, Thap Put District, Phang Nga Province: Cumz 5030, 5033, 5042. Wat Khiriwong, Thap Put District, Phang Nga 


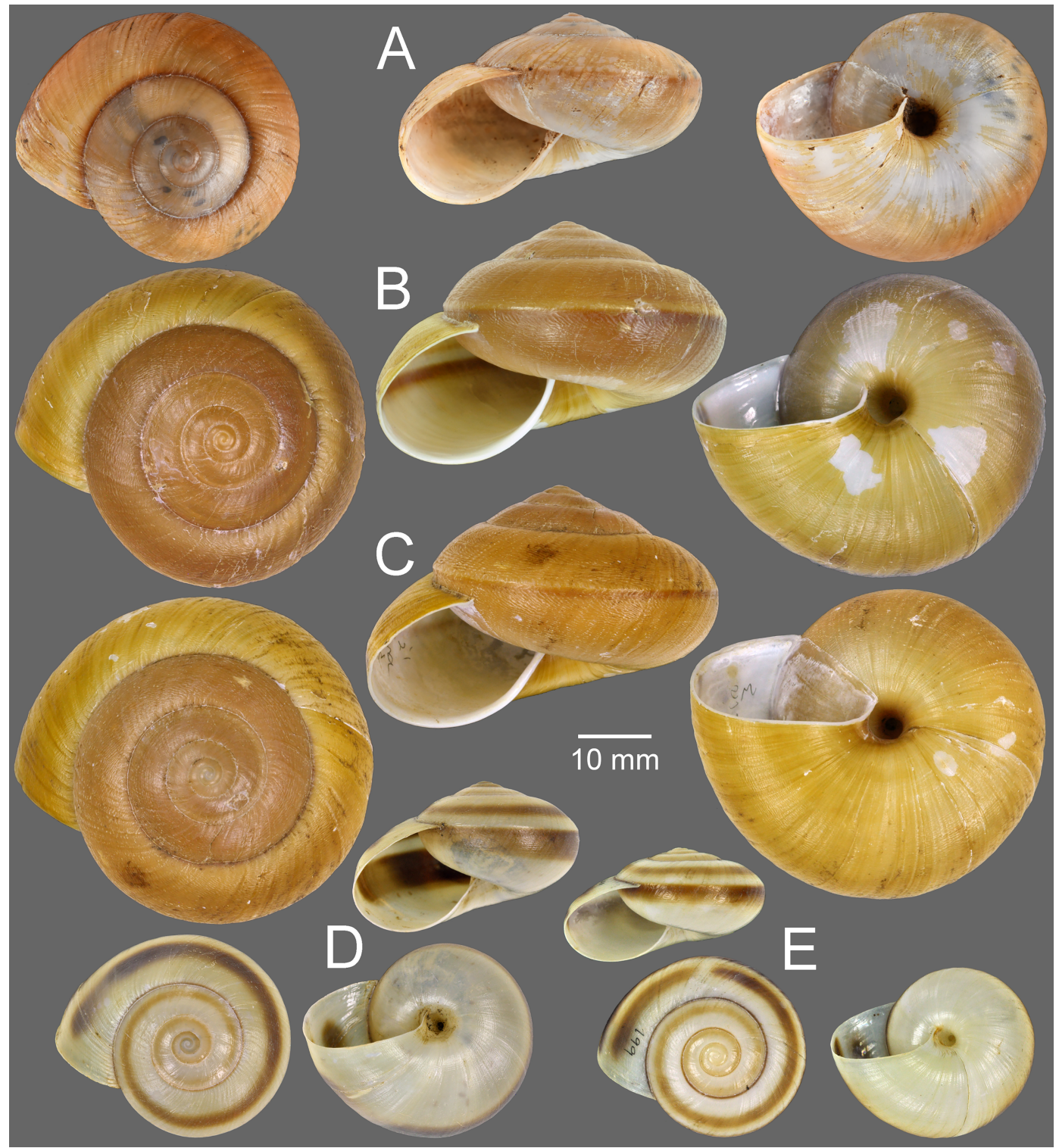

FIGURE 4 Shell characters. A. Hemiplecta lahatensis, specimen CUMZ 5259/2. B, C, Hemiplecta thailandica n. sp.,

(B) holotype Cumz 5095/1 and (C) specimen cumz 5098 from Chanthaburi Province. D, E. Hemiplecta ligorica n. sp., (D) holotype cumZ 5093/1 and (E) paratype CUMZ 5087 from the type locality.

Province: CUMz 5022, 5023, 5082. Khao Sok National Park, Suratthani Province: CUMZ 5034, 5041, 5043. Wat Sathit Khirirom, Khiriratnikhom District, Suratthani Province: CUMz 5020, 5027, 5040. Klong Saeng Wildlife Sanctuary, Suratthani Province: 5029. Rajjaprabha Reservoir, Ban Takhun District, Suratthani Province: cumz 5O26, 5031, 5037.

\section{Description}

Shell (fig. 3A, B). Shell relatively large (width up to $50.0 \mathrm{~mm}$, height up to $25.0 \mathrm{~mm}$ ), depressed conic, thickened and sinistral. Whorls 6-7, increasing regularly, nearly flattened, with shallow suture. Spire convex; apex acute; embryonic shell smooth; following whorls with thin growth lines 


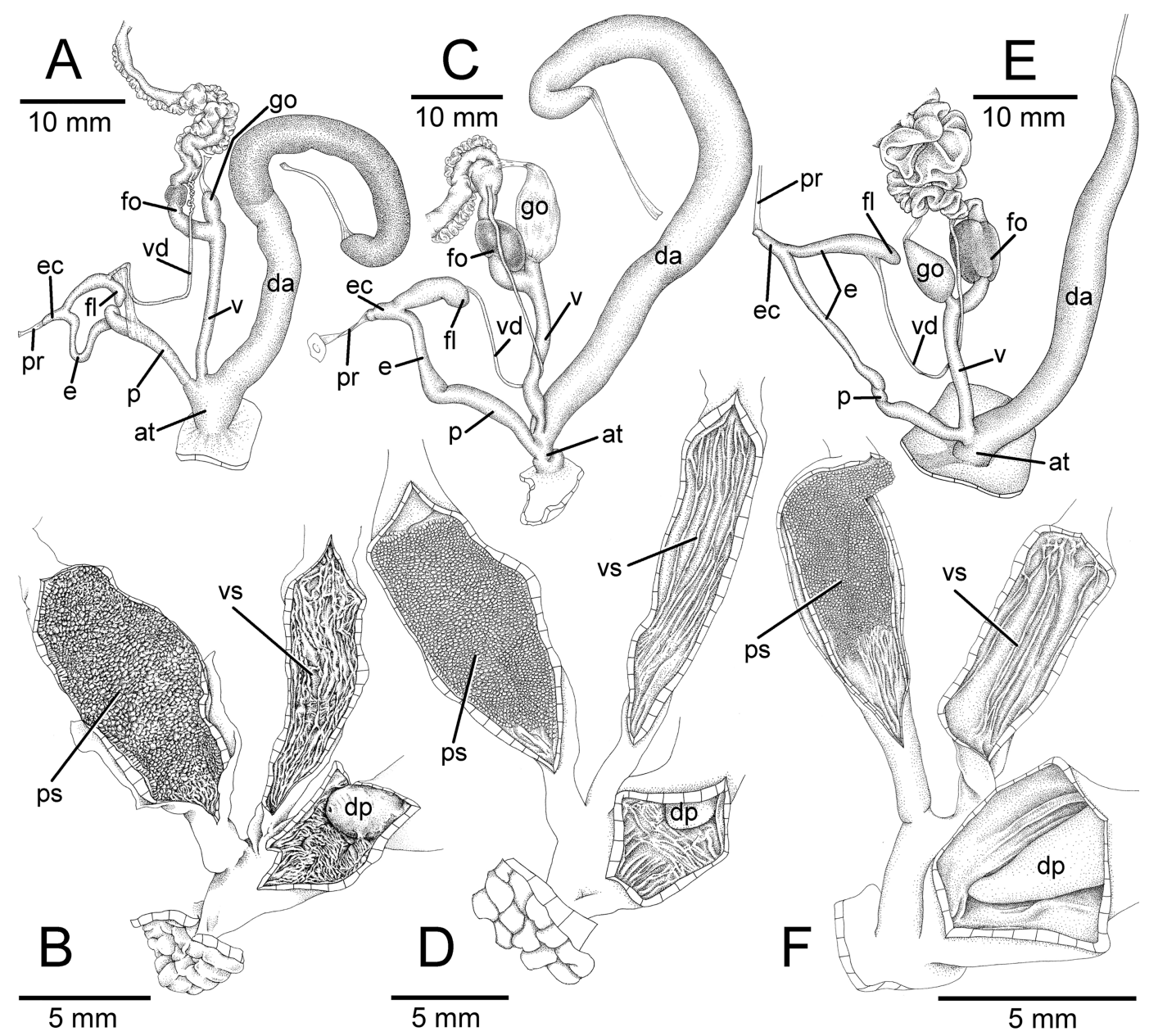

FIGURE 5 Genital characters. A, B. Hemiplecta retrorsa, CUMZ 5094 from Ranong Province. C, D. Hemiplecta thailandica n. sp., holotype CUMZ 5095/1 from the type locality. E, F. Hemiplecta ligorica n. sp., paratype CUMz 5087 from the type locality. A, E, C. Male and female genital organs. B, D, F. internal wall sculpture of penis, vagina and dart apparatus chamber. Abbreviations: at, atrium; da, dart apparatus; dp, dart papilla; e, epiphallus; ec, epiphallic caecum; fl, flagellum; fo, free oviduct; go, gametolytic organ; p, penis; ps, penial sculpture; pr, penial retractor muscle; v, vagina; vd, vas deferens; vs, vaginal sculpture.

and spirally undulated surface sculpture. Periostracum thin corneous. Shell color monochrome brownish to yellowish-brown. Last whorl angular with strong and sharp peripheral keel that diminishes close to aperture. Aperture little descending, broadly ovate-lunate; lip simple to thickened in adult specimens. Columella slightly dilated; parietal callus thin and translucent. Umbilicus narrowly open and deep.
Genitalia (fig. 5 A, B). Atrium very short. Penis a long, slender, cylindrical tube and enclosed by a thin penial sheath. Epiphallus about as long as penis length. Epiphallic caecum short, straight; penial retractor muscle thin and attached to the tip. Flagellum short and little curved. Vas deferens a narrow tube connecting free oviduct and epiphallic-flagellum junction. Internal wall of penis exhibits closely packed papillae over nearly entire penis length; penial verge absent. 

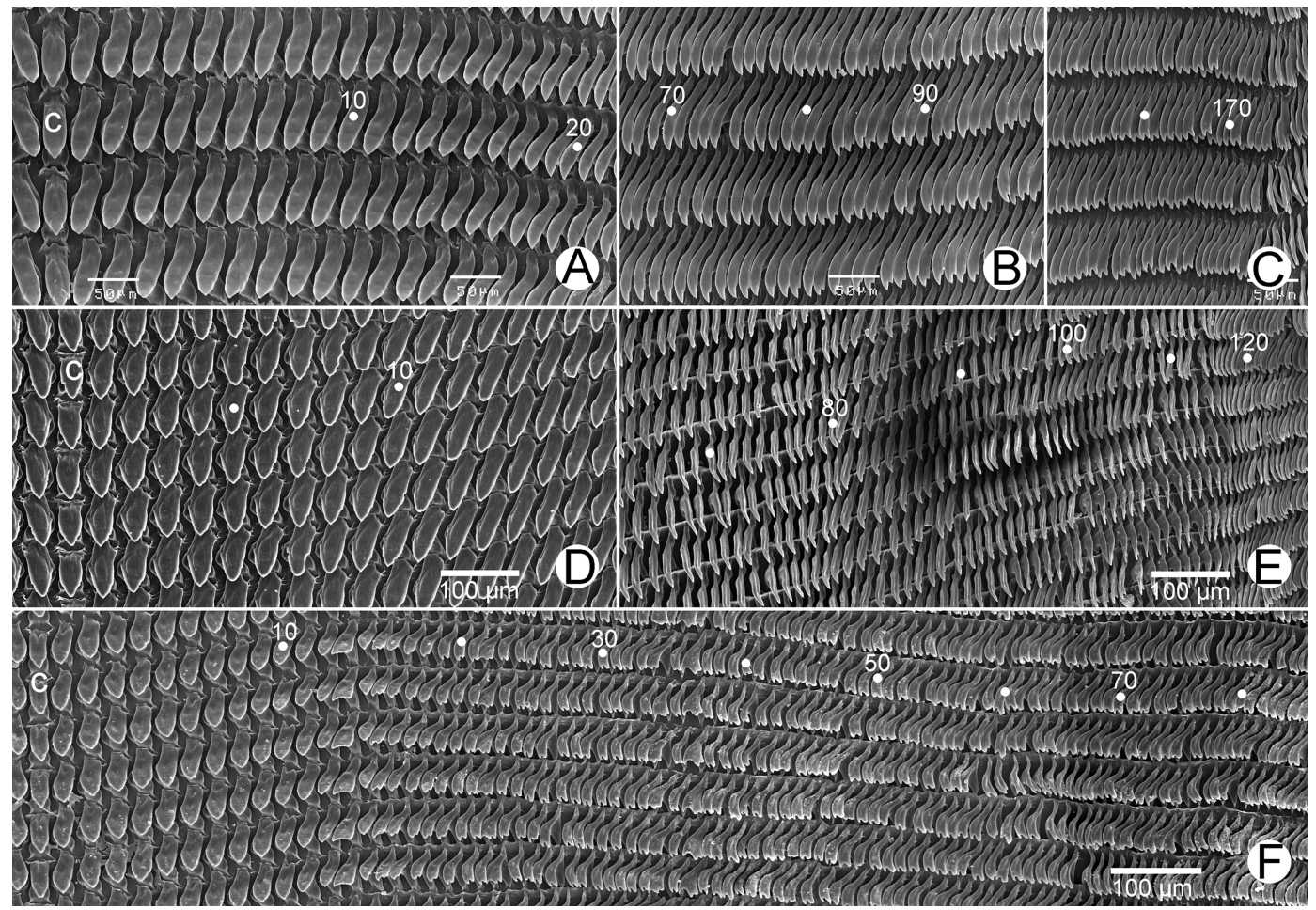

FIGURE 6 SEM images of radula. A-C. Hemiplecta retrorsa, CUMZ 5094 from Ranong Province, (A) central and inner lateral teeth, (B) outer lateral teeth, and (C) outer marginal teeth. D, E. Hemiplecta thailandica $\mathrm{n}$. sp., holotype CUMZ 5095/1 from the type locality, (D) central and lateral teeth, and (E) lateral teeth and marginal teeth. F. Hemiplecta ligorica n. sp., paratype CUMz 5087 from the type locality. Central tooth indicated by ' $\mathrm{C}$ '. Numbers indicate the tooth order from lateral to marginal end.

Vagina long, about same length as penis, cylindrical and similar diameter to penis. Internal wall of vagina possesses irregular vaginal pilasters. Dart apparatus a long muscular cylinder; dart papilla short, conic, with a smooth surface. Gametolytic organ small, globular. Free oviduct short and surrounded by thickened blackish muscular tissue (pinkish in fresh specimens) at distal end.

Radula (fig. 6A-C). Teeth arranged in V-shaped rows with approximately 391 (195-(6o-70)-1(6o-70)-195) teeth. Central tooth symmetric unicuspid and sword-shaped with dull head. Lateral teeth asymmetric unicuspid, sword-shaped, and inclined towards central tooth. Marginal teeth start from tooth $60-70$, elongate sword-shaped, apically bicuspid; endocone and ectocone small with pointed cusp. Outermost teeth shorter and smaller than inner teeth.

Remarks. This species was originally described from southeastern Myanmar, with large shell and strong peripheral keel. The specimens from southwestern peninsular Thailand agree well with the type specimens of this species. In Thailand, this species is known mainly from the western region along the Tenasserim Range in Kanchanaburi, Prachuap Khirikhan, Chumphorn, Ranong, Phang Nga and Suratthani Provinces. This species can be distinguished from $H$. salangana by its angular last whorl with strong keel on periphery, and without a spiral band. In contrast, $H$. salangana tends to have a 
rounded last whorl, and usually has a narrow brownish spiral band on periphery.

\section{Hemiplecta salangana (Martens, 1883)}

(figs 1, $3 \mathrm{C}, \mathrm{D}$ )

Nanina salangana Martens, 1883:134-136, pl. 25, figs 8-12. Type locality: insulam Salanga (Junk Ceilon) ad oran occidentalem peninsulae Malaccanae [Phuket Province, Thailand and Peninsular Malaysia].

Dyakia salangana: Laidlaw, 1931: 191. Laidlaw, 1933: 226. Benthem Jutting, 196o: 17, 20. Berry, 1963: 14, pl. 9, fig. 61. Laidlaw, 1963: 145, 146. Chang, 1996: 4, fig. 1.

Hemiplecta salangana var. martensi Collinge, 1903: 209. Type locality: Bukit Bersa.

Dyakia salangana salangana: Maassen, 2001: 106, 107.

Dyakia salangana martensi: Maassen, 2001:107. Ariophanta trangensis Thach and Huber in Thach, 2020: 36, 37, figs 446-447. Type locality: Suburb of Trang City, Trang Province, Thailand. New Synonym

Material examined. Type material: syntype of Nanina salangana ZMB/Moll 32578 (2 shells; fig. ${ }_{3} \mathrm{C}$ ) from Salanga; possible syntype ZMB/Moll 57522 (1 shell) from Salanga Hinterindien; possible syntype SMF 165021 (1 shell) from Salanga; syntype of Hemiplecta salangana var. martensi Collinge, 1903, NHMUK 1904.5.26.18-19 (2 shells) from Bukit Bersa. Non-type material: MALAYSIA: Bukit Chuping, Perlis $\left(6^{\circ} 29^{\prime} 41.1\right.$ N, $100^{\circ} 16^{\prime}$ o1.o"E): CUMZ 5006, 5076, 5097. Gunung Kilian, Perlis: cumz 4958. Kampung Wang Kelian, Perlis (6 ${ }^{\circ} 40^{\prime} 55.1^{\prime \prime} \mathrm{N}, 100^{\circ} 11^{\prime} 15.2$ "E): CUMZ 4994. Pulau Langgun Island, Langkawi, Kedah: CUMZ 4992. Langkawi Island, Kedah: CUMZ 4962, 4968, 4981, 4999, 5001. THAILAND: Kathu waterfall, Kathu District, Phuket Province: CUMz 4967 (fig. 3D), 4973. Tone Sai
Waterfall, Thalang District, Phuket Province: CUMZ 4952. Koh Lanta, Krabi Province: CUMZ 5008, 5011, 5015. Sra Morakot, Khlong Thom District, Krabi Province: CuMz 498o, 5007. Tam Tab Prik, Krabi Province: cuMz 4970. Wat Tam Sue, Muang District, Krabi Province: CUMZ 4951, 4997, 5017, 5077. Botanic Garden, Trang Province: CUMz 4957, 4965, 4985. Khao Huay Haeng, Huai Yot District, Trang Province: CUMZ 4982, 4995. Khao Pra Yod, Huai Yot District, Trang Province: CuMZ 4979. Sai Rung Waterfall, Pa-lian District, Trang Province: CuMZ 5016. Tam Chang Hai, Na Young District, Trang Province: CUMz 4971. Khao Auk Taru, Muang District, Phatthalung Province: CuMz 4998, 5010, 5018. Khao Poo-Chao, Srinagarindra District, Patthalung Province: CUMZ 4977, 4984, 4991. Budha Kodome, Srinagarindra District, Patthalung Province: CUMz 5005, 50o9. Tam Malai, Muang District, Patthalung Province: CuMz 5012. Tam Praya Hong, Kong Ra District, Patthalung Province: CUMZ 4950, 4974. Tam Su-mano, Srinagarindra District, Patthalung Province: CUMz 4996. Tam Wang Thong, Khuan Khanun District, Phatthalung Province: CUMZ 4953, 4955, 4964, 5013. Khuan Kaloung District, Satun Province: CUMZ 4989. La-ngu District, Satun Province: CuMz 4966, 4978. Tale Bann National Park, Khuan Don District, Satun Province: CUMZ 4972, 4976, 4983. Tam Khantiphol, Thung Wa District, Satun Province: cumz 4959. Tam Tone Din, Khuan Don District, Satun Province: CUMz 4947, 4969. Tarutao, La-ngu District, Satun Province: CUMZ 4946, 4949, 4956, 4963, 4993, 5003, 5004. Tone Pariphat Waterfall, Rattaphum District, Sogkhla Province: CUMZ 5014. Tam Sri Kesorn, Rattaphum District, Songkhla Province: CUMz 4954. Wat Charoen Pu-pha, Rattaphum District, Songkhla Province: CUMZ 4975, 500o. Khao Loop Chang, Sadao District, Songkhla Province: CUMZ 4920. 


\section{Description}

Shell (fig. $3 \mathrm{C}, \mathrm{D}$ ). Shell relatively large (width up to $45.0 \mathrm{~mm}$, height up to $24.0 \mathrm{~mm}$ ), depressed conic, thickened and sinistral. Whorls 6-7, increasing regularly, convex, with wide and depressed suture. Spire convex; apex acute; embryonic shell smooth; following whorls with very thin growth lines and spirally undulated sculpture. Periostracum thin corneous to brownish. Shell color monochrome brownish to yellowish-brown, a narrow brown peripheral band usually present. Last whorl wellrounded. Aperture little descending, broadly ovate-lunate; lip simple to thickened in adult specimens. Columella slightly dilated; parietal callus thin and translucent. Umbilicus narrow and deep.

Genitalia. The external genital organs were described in Sutcharit et al. (2012: fig. 2a, b). Internal wall of penis exhibits closely packed papillae distally that abruptly cease proximally, close to atrium; penial verge absent. Internal sculpture of vagina with thin and smooth longitudinal sculpture; internal surface of amatorial organ smooth.

Radula. The radula morphology was briefly described by Sutcharit et al. (2012: fig. 2d, e). The distinct characters are each row with about 360 teeth $\left(181-\left(15^{-20}\right)-1-\left(15^{-20}\right)-185\right)$. Central tooth unicuspid triangular. Lateral teeth unicuspid, oblique, triangular and inclined towards central tooth. Marginal teeth start from tooth ${ }_{15}^{-20}$, elongate bicuspid, endocone and ectocone small with round head. Outermost teeth shorter and smaller than inner teeth.

Remarks. Hemiplecta salangana is known from several localities in the southern part of peninsular Thailand and in the north of Malaysia. This species can be distinguished from $H$. retrorsa by its relatively smaller and more depressed shell, last whorl well-rounded to weakly angular, and usually with narrow dark brown spiral band on periphery. External features of soft body are similar to those of $H$. retrorsa, only with paler brownish color over entire body compared to $H$. retrorsa.

The "Ariophanta trangensis Thach and Huber, 2020" was recently described from southern Thailand based solely on shell features. The holotype of this species shows no essential differences from the syntype of $H$. salangana and specimens recorded from the western coast of southern Thailand. In addition, the type localities are within the same geographical ranges, and the phylogenetic result shows no genetic subdivision within the wide geographical range of $H$. salangana. Therefore, we have synonymized "Ariophanta trangensis" as a junior synonym of $H$. salangana.

\section{Hemiplecta lahatensis (Morgan, 1885)}

(figs 1, 3E, 4A)

Helix lahatensis Morgan, 1885 b: 68. Type locality: forêt située entre Lahat et Ipoh.

Ariophanta lahatensis: Morgan, 1885a: 382, pl. 6, fig. 4.

Dyakia lahatensis: Laidlaw, 1931: 193. Laidlaw, 1963: 142. Chang, 1996: 5 with text figure.

Material examined. Type material: syntype MNHN-IM-200o-22834 (3 shells; fig. 3E) from Royaume de Pérak, vallée de Kinta [Kinta District, Perak State, Malaysia]. Non-type material: MALAYSIA: Gua Bewah, Kenyir Lake, Terrengganu ( $4^{\circ} 50^{\prime} 43.7^{\prime \prime} \mathrm{N}, 102^{\circ} 43^{\prime} 14.6$ "E), Cumz 5258. Gua Matu Madu, Gua Musang, Kelantan ( $\left.4^{\circ} 50^{\prime} 13.4^{\prime \prime} \mathrm{N}, \quad 1^{\circ}{ }^{\circ} 56^{\prime} 56.3^{\prime} \mathrm{E}\right)$ cUMz 5259/1, 5259/2 (fig. 4A).

\section{Description.}

Shell (figs $3 \mathrm{E}, 4 \mathrm{~A}$ ). Shell small (width up to $40 \mathrm{~mm}$, height up to $24 \mathrm{~mm}$ ), depressed conic, thickened and sinistral. Whorls $5^{-6}$, increasing 
regularly, nearly flattened, with very wide and shallow suture. Spire convex; apex acute; embryonic shell smooth; following whorls with thin growth lines and spirally undulated sculpture. Periostracum thin corneous. Shell color brownish to yellowish-brown, with thin, brown peripheral band. Last whorl rounded, with very weak peripheral keel that weakens close to aperture. Aperture straight, broadly ovate-lunate; lip simple to thickened in adult specimens. Columella slightly dilated; parietal callus thin and translucent. Umbilicus relatively wide and deep.

Remarks. Morgan (1885b) seems to have described $H$. lahatensis based on juvenile specimens, where the syntype (fig. $3 \mathrm{E}$ ) has a very thin shell and pale brown shell color, strong peripheral keel, and very thin and sharp apertural lip. These traits appear in both $H$. retrorsa and $H$. salangana at similar growth stages. The phylogenetic tree shows a distinct clade of two specimens from Kelantan (H8o) and Terengganu $\left(\mathrm{H}_{78}\right)$, with high support. This clade is recovered as a sister group to the $H$. salangana clade with fairly high support. The average genetic divergence of this clade from $H$. salangana is about $5.83 \%$, which is comparable to that of interspecific genetic divergence of $6.67 \%$ within this sinistral Hemiplecta clade (table 2). Therefore, we propose this clade as a distinct species and recognize it as $H$. lahatensis. Although $H$. lahatensis tends to have a very similar shell morphology to $H$. salangana; the main distinguishing character states are the slightly smaller size, with prominent irregular growth lines both above and below the periphery. Unfortunately, we lack reproductively mature specimens, and therefore refrain to re-describe the genitalia of this species. Additional topotypic and mature specimens are necessary to clarify the status and the unique characters of this species.

\section{Hemiplecta thailandica Sutcharit and} Panha, n. sp.

Zoobank: urn:lsid:zoobank.org:pub:C1o2ECB3${ }_{9} \mathrm{CFC}-4 \mathrm{AE1} 191 \mathrm{Bo}-2 \mathrm{AD} 7 \mathrm{AF}_{7} \mathrm{Co} 6 \mathrm{CC}$

(figs 1, 4B, C, 5C, D, 6D, E)

Type material examined. Holotype CUMz 5095/1 (width $50.1 \mathrm{~mm}$, height $29.1 \mathrm{~mm}$; fig. 4B). Paratypes. Same data as holotype: CUMZ 5047 (1 shell), 5049 (1 shell), 5052 (4 shells), 5057 (1 shell), 5063 (3 (shells), 5071 (11 shells), 5072 (13 shells), 5073 (10 shells), 5095/2 (3 specimens in ethanol), NHMUK (2 shells), SMF (2 shells).

Other material examined. THAILAND: Klong Keaw Waterfall, Bo Rai District, Trat Province: CUMZ 5048. Wat Khao Sukim, Tha Mai District, Chanthaburi Province: cumZ 5050, 5053, 5054, 5056, 5060, 5064, 5067, 5069. Makok Waterfall, Khlung District, Chanthaburi Province: CUMZ 5051, 5055, 5059, 5062, 5066, 5०68, 5०75, 5०78, 5०8०. Aow-Beng Waterfall, Makham District, Chanthaburi Province: CUMZ 5058. Hin Dard Waterfall, Pong Namron District, Chanthaburi Province: CUMZ 5061. Plieu Waterfall, Chanthaburi Province: CUMZ 5098 (fig. 4C). Sib-ha Chan Waterfall, Kaeng Hang Maeo District, Chanthaburi Province: CUMZ 5065, 5079. Boy Scout Camping area, Khao Khitchakut District, Chanthaburi Province: CUMZ 5074.

Type locality. The primary evergreen forest at Khao Soidao, Soidao District, Chanthaburi Province $\left(12^{\circ} 55^{\prime} 19.2^{\prime \prime} \mathrm{N} 102^{\circ} 14^{\prime} 51.6^{\prime \prime} \mathrm{E}\right)$.

Etymology. The species name "thailandica" refers to the type locality of this new species in Chanthaburi Province, Thailand.

Diagnosis. Large and low conic shell with brown to brownish yellow shell color, rounded last whorl with narrow dark brown spiral band 
on periphery. Penial sculpture with small penial papillae arranged over nearly entire penis length.

\section{Description}

Shell (fig. $4 \mathrm{~B}, \mathrm{C}$ ). Shell large (width up to $55.0 \mathrm{~mm}$, height up to $35.0 \mathrm{~mm}$ ), low conic, thickened and sinistral. Whorls 6-7, increasing regularly, convex, with depressed suture. Spire convex; apex acute; embryonic shell smooth; following whorls with irregular growth lines and spirally undulated sculpture. Periostracum thin corneous to brownish. Shell color brownish to yellowish brown, and with dark brown band on periphery. Last whorl with rounded to weak peripheral keel. Aperture descending; broadly ovate-lunate; lip simple to thickened in adult specimens. Columella slightly dilated; parietal callus thin and translucent. Umbilicus narrow and deep.

Genitalia (fig. 5C, D). Atrium short. Penis a long, slender and cylindrical tube. Epiphallus about same length as penis. Epiphallic caecum short, straight; penial retractor muscle thin and attached at the tip. Flagellum very short and enlarged. Vas deferens a narrow tube connecting the free oviduct and epiphallic-flagellum junction. Internal wall of penis exhibits closely packed papillae over nearly entire penis length; penial verge absent.

Vagina long, about same length as penis, cylindrical and with a similar diameter as the penis. Internal wall of vagina corrugated, forming a thin and smooth longitudinal pilasters. Dart apparatus a very long and enlarged muscular cylinder; dart papilla short, conic with smooth surface. Gametolytic organ large, of globular shape. Free oviduct long and surrounded by thickened blackish (pinkish in fresh specimens) tissue around the middle.
Radula (fig. 6D, E). Each row with about $25 \mathrm{O}+$ teeth $(+120-(70-80)-1-(70-80)-130+)$. Central tooth unicuspid triangular with pointed head. Lateral teeth unicuspid, oblique and inclined towards central tooth; inner teeth with triangular shape; outer teeth much elongated and similar to marginal teeth. Marginal teeth start from tooth 70-80, elongate bicuspid; endocone large and ectocone small with pointed head.

Remarks. This new species is mainly distributed in the eastern part of Thailand in Chanthaburi and Trat Provinces, and probably in the Cardamom Mountains of Cambodia (Sutcharit et al., 2020). Hemiplecta thailandica n. sp. can be distinguished from $H$. retrorsa and $H$. salangana in having a relatively larger shell, more elevated spire, more depressed suture, a well-rounded last whorl, with dark brown spiral band on periphery, which is only slightly descending near aperture.

\section{Hemiplecta ligorica Sutcharit and Panha,}

n. sp.

Zoobank: urn:lsid:zoobank.org:act:13 $\mathrm{C}_{3} \mathrm{CF}$ oFo33A-4B45-9474-oABE79A6FF66

(figs $1,4 \mathrm{D}, \mathrm{E},{ }_{5} \mathrm{E}, \mathrm{F}, 6 \mathrm{~F}$ )

Type material examined. Holotype CUMz 5093/1 (width $31.8 \mathrm{~mm}$, height 19.3 mm; fig. 4D). Paratypes. Same data as holotype: CUMZ 5087 (1 specimen in ethanol; fig. 4E), 5090 (6 shells), 5093/2 (2 shells), NHMU K (1 shell), SMF (1 shell).

Other material examined. THAILAND: Khao Phanom Wang, Kanchanadit District, Suratthani Province: CUMZ 5089. Krung Ching Waterfall, Nop Phitam District, Nakhon Si Thammarat Province: CUMZ 5083, 5084, 5085, 5092. Tam Lord, Nop Phitam District, Nakhon Si Thammarat Province: cumz 5o86, $5 \circ 88$. 
Type locality. The limestone hills at Tam Khao Lek, Nop Phitam District, Nakhon Si Thammarat Province, Thailand $\left(8^{\circ} 46^{\prime}{ }^{\prime} 5.6^{\prime \prime} \mathrm{N}\right.$, $\left.99^{\circ} 43^{\prime} 38.5^{\prime \prime} \mathrm{E}\right)$.

Etymology. For the historical name of Nakhon Si Thammarat Province, where the type locality is situated.

Diagnosis. Small, sinistral helicoild shell with whitish color, rounded last whorl with dark brown to brownish spiral band on periphery and upper shell surface. Penial sculpture with small papillae arranged over about half of penis length.

\section{Description}

Shell (fig. 4D, E). Shell small (width up to $32.0 \mathrm{~mm}$, height up to $20.0 \mathrm{~mm}$ ), depressed conic, thickened and sinistral. Whorls $5^{-6}$, increasing regularly, little convex, with very wide and depressed suture. Spire convex; apex acute; embryonic shell smooth; following whorls with thin growth lines and spirally undulated sculpture. Periostracum thin and transparent. Shell color whitish to pale brown, usually with wide blackish to dark brown peripheral band just below periphery, and narrow brown spiral band on upper part of last whorl. Last whorl usually well-rounded to little angular. Aperture little descending, ovate-lunate; lip simple to thickened in adult specimens. Columella slightly dilated; parietal callus thin and translucent. Umbilicus narrowly open and deep.

Genitalia (fig. 5 E, F). Atrium very short. Penis a short, slender and cylindrical tube. Epiphallus long, about three times the penis length. Epiphallic caecum short, straight; penial retractor muscle thin and attached to the tip. Flagellum very short. Vas deferens a narrow tube connecting the free oviduct and epiphallic-flagellum junction. Internal wall of penis exhibits closely packed papillae over about half of penis length that abruptly cease close to atrium; penial verge absent.

Vagina long, about two times the length of penis, cylindrical and its diameter similar to that of penis. Internally vagina possesses few corrugated pilasters, which are thin and smooth longitudinal pilasters. Dart apparatus a long muscular cylinder; dart papilla long, conic, with a smooth surface. Gametolytic organ large, of globular shape. Free oviduct long and surrounded by thickened blackish tissue (pinkish in fresh specimens) at distal end.

Radula (fig. 6F). Each row with $240+$ teeth $\left(+120-\left(15^{-20}\right)-1-\left(15^{-20}\right)-120+\right)$. Central tooth unicuspid triangular with rounded head. Lateral teeth unicuspid, oblique, triangular and inclined towards central tooth. Marginal teeth start from tooth $15^{-20}$, bicuspid, endocone and ectocone small with round head.

Remarks. Hemiplecta ligorica n. sp. is known from several localities in limestones outcrops in Suratthani and Nakhon Sri Thammarat Provinces. They tend to be distributed along the Khao Luang range in moist to dry evergreen forest. This new species differs from all other sinistral species in having a relatively smaller, pale brownish to whitish shell with two dark brown spiral bands: one on the periphery and another below the periphery.

\section{References}

Albers, J.C. (1850) Die Heliceen, nach natürlicher Verwandtschaft systematisch geordnet. Verlag von Th. Chr.Fr.Enslin, Berlin. www.biodiversitylibrary. org/item/43756\#page/7/mode/1up.

Albers, J.C. (1860) Die Heliceen, nach natürlicher Verwandtschaft systematisch geordnet. Verlag von Wilhem Engelmann, Berlin. www. biodiversitylibrary.org/item/42934\#page/6/ mode/1up. 
Ancey, C.-F. (1887) Description of new genera or subgenera of Helicidae. Conch. Exc., 1, 53-54.

Asami, T., Cowie, R.H. \& Ohbayashi, K. (1998) Evolution of mirror images by sexually asymmetric mating behavior in hermaphroditic snails. Am. Nat., 152, 225-236. doi. org/10.1086/286163.

AVMA. (2013) AVMA Guidelines for the Euthanasia of Animals. American Veterinary Medical Association. Available online at https://www. avma.org/KB/Policies/Documents/euthanasia. pdf. [Accessed on 2 February 2018].

Baker, H.B. (1941) Zonitid snails from Pacific Islands, Part 3. Genera other than the Microcystinae. Bernice P. Bishop Mus. Bull., 166, 205-346.

Batenburg, F.H.D. van \& Gittenberger, E. (1996) Ease of fixation of a change in coiling: computer experiments on chirality in snails. Heredity, 76, 278-286. https://doi.org/10.1038/ hdy.1996.41.

Beck, H. (1837) Index Molluscorum Praesentis Aevi Musei Principis Augustissimi Christiani Frederici. Hafniae, Hanover.

Benthem Jutting, W.S.S. van. (1960) Some notes on land and freshwater Mollusca of Malaya. Basteria, 24, 10-20.

Berry, A.J. (1963) An introduction to the nonmarine molluscs of Malaya. Malayan Nat. J., 17, $1-18$.

Blanford, W.T. \& Godwin-Austen, H.H. (1908) Mollusca: Testacellidae and Zonitidae. In: Bingham C.T. (Ed.) The Fauna of British India including Ceylon and Burma. Taylor and Francis, London.

Chang, S.Y. (1996) On Dyakia lahatensis (de Morgan, 1885) and Dyakia kintana (de Morgan, 1885). Papustyla, 10(4), 5-9.

Collinge, W.F. (1902) On the non-operculate land and freshwater molluscs collected by members of the "Skeat Expedition" in the Malay Peninsula, 1899-1900. J. Malac., 9, 71-95.

Collinge, W.E. (1903) Report on the non-operculate land Mollusca. Fasci. Malays: Zool., 2, 205-218.
Criscione, F., Law., M.L. \& Köhler, F. (2012) Land snail diversity in the monsoon tropics of Northern Australia: revision of the genus Exiligada Iredale, 1939 (Mollusca: Pulmonata: Camaenidae), with description of 13 new species. Zool. J. Linn. Soc., 166, 689-722. doi: 10.1111/j.1096-3642.2012.00863.x.

Crosse H. 1867. Description d'un genre nouveau de la famille des Fissurellidae. J. Conchyl, 15, 74-78. Danaisawadi, P., Asami, T., Ota, H., Sutcharit, C. \& Panha, S. (2016) A snail-eating snake recognizes prey handedness. Sci. Rep., 6, 23832. doi. org/10.1038/srep23832.

Davison, A., Blackie, R.L.E. \& Scothern, G.P. (2009) DNA barcoding of stylommatophoranland snails: a test of existing sequences. Mol. Ecol. Resour., 9, 1092-1101. doi:10.1111/j.1755-0998.2009.o2559.x.

Davison, A., Chiba, S., Barton, N.H. \& Clarke, B. (2005) Speciation and gene flow between snails of opposite chirality. PLoS One, 3, 1559-1571. doi. org/10.1371/journal.pbio.0030282.

Dunn, C.P. (2003) Keeping taxonomy based in morphology. Trends Ecol. Evol., 18, 270-271. doi: 10.1016/So169-5347(03)ooo94-6.

Fischer, H. \& Dautzenberg, P. (1904) Catalogue des mollusques terrestres et fluviatiles de l'IndoChine orientale cites jusqu' à ce jour. In: Pavie A. (Ed) Mission Pavie, Recherches sur Histoire Naturelle de l'Indo-Chine Orientale Etudes diverses 3, pp. 390-45o. Ernest Leroux, Éditeur, Paris.

Folmer, O., Black, M., Hoeh, W., Lutz, R. \& Vrijenhoek, R. (1994) DNA primers for amplification of mitochondrial cytochrome $\mathrm{c}$ oxidase subunit I from diverse metazoan invertebrates. Mol. Mar. Biol. Biotechnol., 3, 294-299.

Gittenberger, E. 1988. Sympatric speciation in snails: A largely neglected model. Evolution, 42, $826-828$.

Gittenberger, E., Hamann, T.D. \& Asami, T. 2012. Chiral speciation in terrestrial pulmonate snails. PloS One, 7, e34005. doi.org/10.1371/ journal.pone.0034005. 
Godwin-Austen, H.H. (1883, 1898, 1907 [1883-1907]) Land and Freshwater Mollusca of India, including South Arabia, Baluchistan, Afghanistan, Kashmir, Nepal, Burmah, Pegu, Tenasserim, Malay Peninsula, Ceylon, and other Islands of the Indian Ocean (Volume 1: 1-257, pls 1-62). Supplementary to Messrs. Theobald and Hanley's Conchologia Indica. Taylor and Francis, London.

Godwin-Austen, H.H. (1891) On a collection of land shells made in Borneo by Mr. Everett, with descriptions of supposed new species. Part II. Zotinidae and Helicinidae. Proc. Zool. Soc. Lond., 59, 22-47.

Godwin-Austen, H.H. (1900) On the anatomy of Hemiplecta floweri E.A. Smith, from Perak, Malays Peninsular; with notes on some other eastern genera. Proc. Malac. Soc. Lond., 4, $31-36$.

Godwin-Austen, H.H. (1919) On the position of Helix distincta Pfr. of Siam. Rec. Indian Mus., 16, 199-202.

Gómez, B.J. (2001) Structure and functioning of the reproductive system. In: Baker G.M. (Ed.) The Biology of Terrestrial Molluscs. CABI Publishing, New York.

Gould, A.A. (1843) Description of land mollusks from the province of Tavoy, in British Burmah, collected by Francis Mason. Proc. Boston Soc. Nat. Hist., 1, 137-141.

Gould, A.A. (1844) Description of land mollusks from the province of Tavoy, in British Burmah. Boston J. Nat. Hist., 4, 452-459.

Gray, J.E. (1834) Specimens of several shells, referred to a genus to be separated from Helix under the name of Nanina. Proc. Zool. Soc. Lond., 2, 58-59.

Gude, G.K. \& Woodward, B.B. (1921) On Helicella Férussac. Proc. Malac. Soc. Lond., 14, 174-19o.

Hausdorf, B. (1995) A preliminary phylogenetic and biogeographic analysis of the Dyakiidae (Gastropoda: Stylommatophora) and a biogeographic analysis of other Sundaland taxa. Cladistics, 11, 359-376.
Hausdorf, B. (1998) Phylogeny of the Limacoidea sensu lato(Gastropoda:Stylommatophora).J.Moll. Stud., 64, 35-66. doi.org/10.1093/mollus/64.1.35.

Hebert, P.D.N. \& Gregory, T.R. (2005) The promise of DNA barcoding for taxonomy. Syst. Biol., 54, 852-859. doi.org/10.1080/10635150500354886.

Hirano, T., Kameda, Y., Kimura, K. \& Chiba, S. (2014) Substantial incongruence among the morphology, taxonomy, and molecular phylogeny of the land snails Aegista, Landouria, Trishoplita, and Pseudobuliminus (Pulmonata: Bradybaenidae) occurring in East Asia. Mol. Phylogenet. Evol., 70, 171-181. doi:10.1016/j.ympev.2013.og.o2o.

Hirano, T., Kameda, Y., Kimura, K. \& Chiba, S. (2015) Divergence in the shell morphology of the land snailgenus Aegista (Pulmonata:Bradybaenidae) under phylogenetic constraints. Biol. J. Linn. Soc., 114, 229-241. doi:10.1111/bij.12407.

Hoso, M., Asami, T. \& Hori, M. (2007) Right-handed snakes: convergent evolution of asymmetry for functional specialization. Biol. Lett., 3, 169-173. doi.org/10.1098/rsbl.2006.o6oo.

Hoso, M., Kameda, Y., Wu, S.-P., Asami, T., Kata, M. \& Hori, M. (2010) A speciation gene for leftright reversal in snails results in anti-predator adaptation. Nat. Commun., 1, 133 doi: 10.1038/ ncommsi133.

Huelsenbeck, J.P. \& Hillis, D.M. (1993) Success of phylogenetic methods in the four-taxon case. Syst. Biol., 42, 247-264. doi.org/10.1093/ sysbio/42.3.247.

Hyman,I.,Ho,S.Y.W.\&Jermiin,L.S.(2007)Molecular phylogeny of Australian Helicarionidae, Euconulidae and related groups (Gastropoda: Pulmonata: Stylommatophora) based on mitochondrial DNA. Mol. Phylogenet. Evol., 45, 792-812. doi:10.1016/j.ympev.2007.08.o18.

Hyman, I.T., Lamborena, I. \& Köhler, F. (2017). Molecularphylogenetics and systematic revision of the south-eastern Australian Helicarionidae (Gastropoda, Stylommatophora). Contrib. Zool., 86, 51-95. https://doi.org/10.1163/18759 866-o8601004. 
Hyman, I.T. \& Ponder, W.F. (2010) A morphological phylogenetic analysis and generic revision of Australian Helicarionidae (Gastropoda: Pulmonata: Stylommatophora), and an assessment of the relationships of the family. Zootaxa, 2462, 1-148. doi: doi.org/10.11646/ zootaxa.2462.1.1.

Inkhavilay, K., Sutcharit, C., Bantaowong, U., Chanabun, R., Siriwut, W., Srisonchai, R., Pholyotha, A., Jirapatrasilp, P. \& Panha, S. (2019) Annotated checklist of the terrestrial molluscs from Laos (Mollusca, Gastropoda). ZooKeys, 834, 1-166. doi:10.3897/zookeys.834.288oo.

Jirapatrasilp, P., Tongkerd, P., Jeratthitikul, E., Liew, T.S., Pholyotha, A., Sutcharit, C. \& Panha, S. (2020) Molecular phylogeny of the limacoid snail family Dyakiidae in Southeast Asia, with the description of a new genus and species. Zool. J. Linn. Soc.,.

Johnson, M.S., Clarke, B. \& Murray, J. (1990) The coil polymorphism in Partula suturalis does not favor sympatric speciation. Evolution, 44, 459-464.

Kessing, B., Croom, H., Martin, A., McIntosh, C., McMillan, W.O. \& Palumbi, S. (1989) The Simple Fool's Guide to PCR. Department of Zoology, University of Hawaii, Honolulu.

Köhler, F. (2010) Uncovering local endemism in the Kimberley, Western Australia: description of new species of the genus Amplirhagada Iredale, 1933 (Pulmonata, Camaenidae). Rec. Aust. Mus., 62, 217-284. doi: 10.3853/j.oo67-1975.62.2010.1554.

Köhler, F. (2011a) Australocosmica, a new genus of land snails from the Kimberley, Western Australia (Eupulmonata, Camaenidae). Malacologia, 53, 199-216. doi.org/10.1002/ zoos.201200004.

Köhler, F. (2011b) The camaenid species of the Kimberley Islands, Western Australia (Stylommatophora: Helicoidea). Malacologia, 54, 203-402. doi: 10.4002/040.054.0108.

Köhler, F. (2011c) Descriptions of new species of the diverse and endemic land snail Amplirhagada Iredale, 1933 from rainforest patches across the Kimberley, Western Australia (Pulmonata, Camaenidae). Rec. Aust. Mus., 63, 167-202. doi: 10.3853/j.0o67-1975.62.2010.1554.

Köhler, F. (2012) Taxonomic revision of two endemic land snail genera from the Top End of Northern Australia with remarks on two problematic species named by de Férussac and Le Guillou (Eupulmonata, Camaenidae). Zoosyst. Evol., 88, 53-62. doi.org/10.1002/ zoos.201200oo6.

Köhler, F. \& Criscione, F. (2015) A molecular phylogeny of camaenid land snails from north-western Australia unravels widespread homoplasy in morphological characters (Gastropoda, Helicoidea). Mol. Phylogenet.Evol., 83, 44-55. doi.org/10.1016/j.ympev.2014.11.0o9.

Köhler, F. \& Johnson, M.S. (2012) Species limits in molecular phylogenies: a cautionary tale from Australian land snails (Camaenidae: Amplirhagada Iredale, 1933). Zool. J. Linn. Soc., 165,337-362.doi:10.1111/j.1096-3642.2011.0o81o.x. Köhler, F. \& Shea, M. (2012) Youwanjela, a new genus of land snail from the Kimberley, Western Australia (Eupulmonata: Camaenidae). Zoosyst. Evol., 88, 25-31. doi.org/10.1002/zoos.201200oo4. Köhler, F., Criscione, F., Hallan, A., Hyman, I. \& Kessner, V. (2020) Lessons from Timor: shells are poor taxonomic indicators in Asperitas land snails (Stylommatophora, Dyakiidae). Zool. Scr, in press. doi.org/10.1111/zsc.12449.

Kumar, S., Stecher, G. \& Tamura, K. (2016) MEGA7: molecular evolutionary genetics analysis version 7.0 for bigger datasets. Mol. Biol. Evol., 33, 1870-1874. doi:10.1093/molbev/mswo54.

Laidlaw, F.F. (1931) On a new subfamily Dyakiinae of the Zonitidae. Proc. Malac. Soc. Lond., 19, 190-201.

Laidlaw, F.F. (1933) A list of the land and freshwater Mollusca of the Malay Peninsula. $J$. Malays. Branch R. Asiat. Soc., 11, 211-234.

Laidlaw, F.F. (1963) Notes on the genus Dyakia, with a list of species. J. Conch., 25, 137-151.

Lanfear, R., Frandsen, P.B., Wright, A.M., Senfeld, T. \& Calcott, B. (2016) PartitionFinder 2: New methods for selecting partitioned models of 
evolution for molecular and morphological phylogenetic analyses. Mol. Biol. Evol., 34:772773. doi:10.1093/molbev/msw26o.

Larget, B. \& Simon, D.L. (1999) Markov chain Monte Carlo algorithms for the Bayesian analysis of phylogenetic trees. Mol. Biol. Evol., $16,75^{\circ}-759$.

Lea, I. (1840) Description of nineteen new species of Colimacea. Proc. Am. Philos. Soc., 1, 173-175.

Lukoschek, V., Osterhage, J.L., Karns, D.R., Murphy, J.C. \& Voris, H.K. (2011) Phylogeography of the Mekong mud snake (Enhydris subtaeniata): the biogeographic importance of dynamic river drainages and fluctuating sea levels for semiaquatic taxa in Indochina. Ecol. Evol., 1, 330-342. doi: 10.1002/ece3.29.

Maassen, W.J.M. (2001) A preliminary checklist of the non-marine molluscs of West-Malaysia. "A Handlist". De Kreukel, Extra Editie, 2001, 1-155.

Maassen, W.J.M. (2006) Four new species of terrestrial gastropods from Tonkin, North Vietnam (Gastropoda: Diplommatinidae: Strobilopsidae and Ariophantidae). Basteria, 70, 13-18.

Martens, E. von. (1883) Conchylien von Salanga. Conch. Mitt., 2: 129-154.

Miller, M.A., Pfeiffer, W. \& Schwartz, T. (2010) Creating the CIPRES Science Gateway for inference of large phylogenetic trees. In: Proceedings of the Gateway Computing Environments Workshop (GCE), 14 Nov. 2010, New Orleans, LA, USA.

Mörch, O.A.L. (1872) Catalogue des mollusques terrestres et fluviatiles des anciennes colonies danoides du Golfe du Bengale. J. Chochyl., 20, 303-345.

Morgan, J. de. (1885a) Mollusques terrestres et fluviatiles du royaume de Perak. Bull. Soc. Zool. Fr., 10, 353-428.

Morgan, J. de. (1885b) Note sur quelques espèces nouvelles de mollusques terrestres récruillis dans la Peninsula Malaise. Le Nat., 7, 68-70.

Morgan, J.A., DeJong, R.J., Jung, Y., Khallayoune, K., Kock, S., Mkoji, G.M. \& Loker, E.S. (2002) A phylogeny of planorbid snails, with implications for the evolution of Schistosoma parasites. Mol. Phylogenet. Evol., 25, 477-488. doi.org/10.1016/ S1055-79०3(O2)oo28o-4.

Muadsub, S. \& Pinkaew, N. (2014) Sirindhornia Pinkaew and Muadsub (Lepidoptera: Tortricidae), a new enarmoniine genus from Thailand. Zootaxa, 3869, 53-63. doi: 10.11646/ zootaxa.3869.1.5.

Oheimb, P.V. von, Oheimb, K.C.M. von, Hirano, T., Do, T.V., Luong, H.V., Ablett, J., Pham, S.V. \& Naggs, F. (2018) Competition matters: determining the drivers of land snail community assembly among limestone karst areas in northern Vietnam. Ecol. Evol., 8, 41364149. doi.org/10.1002/ece3.3984.

Páll-Gergely, B., Hunyadi, A., Jochum, A. \& Asami, T. (2015) Seven new hypselostomatid species from China, including some of the world's smallest land snails (Gastropoda, Pulmonata, Orthurethra). ZooKeys, 523, 31-62. doi:10.3897/ zookeys.523.6114.

Panha, S. (1996) A checklist and classification of the terrestrial pulmonate snail of Thailand. Walkerana, 8, 31-40.

Pfeiffer, L. (1850) Beschreibungen neuer Landschnecken. Zeit. Malacozool., 7, 65-80.

Pfeiffer,L.(1856[1854-186o])Novitates Conchologicae. Series prima. Mollusca extramarina. Beschreibung und Abbidung neuer order kritischer Land- und Süsswasser Mollusken. Tome 1 (Lief. 5-8: 49-9o, pls 13-24). Th. Fischer, Cassel.

Pfeiffer, L. (1862) Diagnoses de neuf espèces nouvelles provenant de Siam. J. Conchyl., 10, 39-46.

Pfeiffer, L. (1863) Descriptions of thirty-six new land shells from the collection of $\mathrm{H}$. Cuming, Esq. Proc. Zool. Soc. Lond., 30, 268-278.

Philippi, R.A. (1846) Vier neue konchylinarten. Zeit. Malakozool., 3, 191-192.

Pholyotha, A., Sutcharit, C. \& Panha, S. (2018) The land snail genus Macrochlamys Gray, 1847 from Thailand, with descriptions of five new species (Pulmonata: Ariophantidae). Raffles Bull. Zool., $66,763-781$. 
Pholyotha, A., Sutcharit, C., Tongkerd, P., Jeratthitikul, E. \& Panha, S. (2020) Integrative systematics reveals the new land-snail genus Taphrenalla (Eupulmonata: Ariophantidae) with a description of nine new species from Thailand. Contrib. Zool., in press. doi: 10.1163/18759866-bja1oo13.

Pilsbry H.A. (189o) Manual of Conchology, Structural and Systematic with Illustrations of the Species. Series 2, Volume 6. The Academy of Natural Sciences Philadelphia.

Pilsbry H.A. (190o) Manual of Conchology, Structural and Systematic with Illustrations of the Species. Series 2, Volume 13. The Academy of Natural Sciences Philadelphia.

Reeve, L. (186oa) On two new species of shells from Cambojia. Ann. Mag. Nat. Hist., ser. 3, 6, 203-204.

Reise, H., Benke, M. \& Hutchinson, J.M.C. (2002) A sinistral specimen of the terrestrial slug Arion lusitanicus (Gastropoda: Pulmonata: Arionidae). Malak. Abh. Mus. Terkde. Dresden, 20, 247-252.

Ronquist, F., Teslenko, M., Mark, P., Ayres, D.L., Darling, A., Höhna, S., Larget, B., Liu, L., Suchard, M.A. \& Huelsenbeck, J.P. (2012) MrBayes 3.2: Efficient Bayesian phylogenetic inference and model choice across a large model space. Syst. Biol., 61, 539-542. doi:10.1093/sysbio/syso29.

Schileyko, A.A. (1998) Treatise on recent terrestrial pulmonate molluscs, Part 2: Gastrocoptidae, Hypselostomatidae, Vertiginidae, Truncatellinidae, Pachnodidae, Enidae, Sagdidae. Ruthenica, supp. 2, 129-261.

Schileyko, A.A. (2002) Treatise on recent terrestrial pulmonate mollusks. Part 9. Helicarionidae, Gymnarionidae, Rhysotinidae, Ariophantidae. Ruthenica, supp. 2, 1167-1307.

Schileyko, A.A. (2003) Treatise on recent terrestrial pulmonate mollusks. Part 10. Ariophantidae, Ostracolethidae, Ryssotidae, Milacidae, Dyakiidae, Staffordiidae, Gastrodontidae, Zonitidae, Daudebardiidae, Parmacellidae. Ruthenica, supp. 2, 1309-1466.
Schileyko, A.A. (2011) Check-list of land pulmonate molluscs of Vietnam (Gastropoda: Stylommatophora). Ruthenica, 21, 1-68.

Schileyko, A.A. (2015) Taxonomic position of Helix pernobilis Férussac 1821 and notes on the genus Koratia (Gastropoda: Pulmonata: Ariophantidae). Ruthenica, 25, 15-18.

Schilthuizen, M., Til, A.V., Salverda, M., Liew, T.-S., James, S.S., Elahan, B.B. \& Vermeulen, J.J. (2006) Microgeographic evolution of snail shell shape and predator behavior. Evolution, 6o, 1851-1858. doi: 10.1554/o6-114.1.

Seberg, O., Humphries, C.J., Knapp, S., Stevenson, D.W., Petersen, G., Scharff, N. \& Andersen, N.M. (2003) Shortcuts in systematics? A commentary on DNA-based taxonomy. Trends Ecol. Evol., 18, 63-65. doi: 10.1016/ So169-5347( o2)ooo59-9.

Semper, C. (1870 [1870-1885]) Reisen im Archipel der Philippinen, Theil 2. Wissenschaftliche Resultate. Band 3, Landmollusken. Kreidel, Wiesdaden.

Siriboon, T., Naggs, F., Wade, C.M., Jeratthitikul, E., Tongkerd, P., Jirapatrasilp, P., Panha, S. \& Sutcharit, C. (2020) Phylogenetic relationships of the carnivorous terrestrial snail family Streptaxidae (Stylommatophora: Achatinina) in Thailand and surrounding areas of Southeast Asia. Syst. Biodivers., 18, 720-738, doi: 10.1080/14772000.2020.1783384.

Siriwut, W., Edgecombe, G.D., Sutcharit, C. \& Panha, S. (2015) The centipede genus Scolopendra in mainland Southeast Asia: molecular phylogenetics, geometric morphometrics and external morphology as tools for species delimitation. PLoS ONE, 10(8), eo135355. doi:10.1371/journal.pone.0135355.

Smith, E.A. (1896) Notes on some land shells from Vanbu, Tonkin, with description of two new species. Ann. Mag. Nat. Hist., ser. 6, 17, 128-130.

Solem, A. (1966) Some non-marine mollusks from Thailand, with notes on classification of the Helicarionidae. Spolia Zool. Mus. Haun., 24, 1-110. 
Stamatakis, A. (2014) RAxML Version 8: A tool for phylogenetic analysis and post-analysis of large phylogenies. Bioinformatics, 30, 1312-1313. doi:10.1093/bioinformatics/btuo33.

Stoliczka, F. (1873) On the land-shells of Penang Island, with descriptions of the animals and anatomical notes; part second, Helicacea. $J$. Asiat. Soc. Bengal, 42, 11-38.

Sutcharit, C., Asami, T. \& Panha, S. (2007) Evolution of whole-body enantiomorphy in the tree snail genus Amphidromus. J. Evol. Biol., 20, $661-672$.

Sutcharit, C., Naggs, F., Ablett, J., Sang, P.V., Hao, L. \& Panha, S. (2019) Notes on the sinistral helicoid snail Bertia cambojiensis (Reeve, 1860) from Vietnam (Eupulmonata, Dyakiidae). ZooKeys, 885, 1-14. doi: 10.3897/zookeys.885.38980.

Sutcharit, C., Thach, P., Chhuoy, S., Ngor, P.B., Jeratthitikul, E., Siriwut, W., Srisonchai, R., Ng, T.H., Pholyotha, A., Jirapatrasilp, P. \& Panha, S. (2020) Annotated checklist of the land snail fauna from Southern Cambodia (Mollusca, Gastropoda). ZooKeys, 948, 1-46. doi: 10.3897/ zookeys.948.51671.

Sutcharit, C., Tongkerd, P., Aileen-Tan, S.H. \& Panha, S. (2012) Taxonomic revision of Dyakia janus from peninsular Malaysia (Pulmonata: Dyakiidae), with notes on other sinistrally coiled helicarionoids. Raffles Bull. Zool., 6o, 279-287.

Tautz, D., Arctander, P., Minelli, A., Thomas, R.H. \& Vogler, A.P. (2003) A plea for DNA taxonomy. Trends Ecol. Evol., 18, 70-74. doi.org/10.1016/ So169-5347( o2)0oo41-1.

Thach, N.N. (2020) New Shells of South Asia: Seashells - Freshwater - Land Snails. With one
New Genus and 140 New Species and Subspecies, Reply to comments made in error. $48 \mathrm{Hr}$ Books Company, USA.

Thiele, J. (1931) Handbuch der Systematischen Weichtierkunde. Thiel 1. Jena Verlag von Gustav Fischer, Berlin.

Tumpeesuwan, C., Naggs, F. \& Panha, S. (2007) A new genus and new species of dyakiid snail (Pulmonata: Dyakiidae) from the Phu Phan Range, Northeastern Thailand. Raffles Bull. Zool., 55, 363-369.

Ueshima, R. \& Asami, T. (2003) Evolution: singlegene speciation by left-right reversal. Nature, 425, 679. doi: 10.1038/425679a.

Vermeij, G.J. (1993) A Natural History of Shells. Princeton University Press, Princeton.

Voris, H.K. (2000) Maps of Pleistocene sea levels in Southeast Asia: shorelines, river systems and time durations. J. Biogeogr., 27, 1153-1167. doi:10.1046/j.1365-2699.2000.00489.x.

Woodruff, D.S. (2010) Biogeography and conservation in Southeast Asia: how 2.7 million years of repeated environmental fluctuations affect today's patterns and the future of the remaining refugial-phase biodiversity. Biodivers. Conserv., 19, 919-941. doi: 10.1007/ s10531-010-9783-3.

Zilch, A. (1959 [1959-196o]). Gastropoda, Euthyneura. In: Schindewolf O.H., (Ed.) Handbuch der Paläozoologie, 6:1-6oo. Gebrüder Borntraeger, Berlin.

RECEIVED: 26 JUNE 2020 | REVISED AND ACCEPTED: 23 OCTOBER 2020

EDITOR: D. HUANG 